\title{
FRAGMENTAÇÃO GEOPOLÍTICA: UMA ANÁLISE ESTRUTURAL DAS PROPOSTAS DE SEPARATISMO NO BRASIL
}

\author{
Eduardo Amaral Haddad * \\ Amir Borges Ferreira Neto ${ }^{\dagger}$ \\ Fernando Salgueiro Perobelli ${ }^{\ddagger}$
}

\begin{abstract}
Resumo
Este trabalho tem por objetivo dar luz ao debate sobre a criação dos novos entes federativos, trazendo elementos objetivos sobre a caracterização socioeconômica dos novos espaços geopolíticos e seus respectivos papéis no novo contexto espacial do sistema inter-regional brasileiro. $\mathrm{O}$ artigo traz resultados inéditos para a discussão, buscando, inicialmente, identificar padrões hierárquicos e de dependência espacial e produtiva neste novo contexto federativo. Tais resultados subsidiam a analise subsequente dos impactos da nova configuração das transferências constitucionais, que identifica por meio de simulações com um modelo inter-regional de insumo-produto especialmente calibrado para as 33 regiões consideradas no estudo, não apenas os potenciais ganhadores e perdedores, mas também os mecanismos de interação espacial subjacentes a estes processos.
\end{abstract}

Palavras-chave: Separatismo; Análise exploratória de dados espaciais;

Modelo inter-regional de insumo-produto; Transferências inter-regionais.

\begin{abstract}
This paper aims to shed light to the debate on the creation of new federal entities, bringing objective elements on the socioeconomic characteristics of the new geopolitical areas and their respective roles in the new spatial context of the Brazilian interregional system. The article presents new results for the discussion, initially trying to identify patterns of hierarchical spatial and productive dependency in this new federal design. These results subsidize the subsequent analysis of the impacts of the new configuration of the constitutional transfers, which identifies, through simulations with an interregional input-output model, specially calibrated for 33 regions considered in the study, not only the potential winners and losers, but also the spatial interaction mechanisms underlying these processes.
\end{abstract}

Keywords: Separatism; Exploratory spatial data analysis; Interregional input-output model; Interregional transfers

JEL classification: C21, C67, H77

\footnotetext{
* Universidade de Sao Paulo, bolsista do CNPQ. Email: ehaddad@usp.br

† Universidade Federal de Juiz de Fora. Email: amirneto@gmail.com

‡ Universidade Federal de Juiz de Fora. Bolsista do CNPq e Pesquisador Mineiro FAPEMIG.

Email: fernando.perobelli@ufjf.edu.br
} 


\section{Introdução}

Propostas para criação de novos Estados estão no Congresso desde o início da década de 1990, sendo que é possível dividi-las em dois grupos: as que estão avançadas e as que estão num caráter mais especulativo. As propostas avançadas são as representadas pelos novos Estados do Maranhão do Sul, Gurgueia, Carajás, Tapajós, Rio São Francisco, Mato Grosso do Norte e Triângulo, pois, além de apresentar Projetos de $\operatorname{Lei}^{1}$ encaminhados à Câmara, já foram discutidas em plenário.

As outras propostas, ainda em fase de especulação, seriam a criação dos Territórios Federais do Marajó, Alto Rio Negro e Oiapoque, todos na região Norte, e do Estado de Solimões. Ainda seriam criados os Estados de São Paulo do Leste e Minas do Norte, e recriado o Estado da Guanabara na região Sudeste. Na região Centro-Oeste, além do Mato Grosso do Norte, ainda seriam criados os Estados do Araguaia e do Planalto Central.

Com as propostas avançadas, caso aprovadas, o Brasil passaria a ter 32 Estados além do Distrito Federal. Caso haja uma divisão ainda maior, como sugerido pelas propostas especulativas, o País passaria a ter 39 Estados e três Territórios.

Motivado pela aprovação da Câmara para o plebiscito sobre a criação de novos Estados, este trabalho tem por objetivo dar luz ao debate sobre a criação dos novos entes federativos, trazendo elementos objetivos sobre a caracterização socioeconômica dos novos espaços geopolíticos e seus respectivos papéis no novo contexto espacial do sistema inter-regional brasileiro. Para tanto, o estudo baseou-se na divisão territorial hipotética em que se pressupõe que os Projetos de Lei em discussão na Câmara "vinguem" (Figura 1). Inicialmente, será realizada uma análise exploratória com alguns indicadores socioeconômicos básicos, tais como o PIB, o PIB per capita (PPC), e o índice FIRJAN de Desenvolvimento Municipal (IFDM). A questão da heterogeneidade intraestadual também será verificada. Em seguida, utilizando-se uma matriz de insumo-produto inter-regional considerando as novas unidades da Federação, estimada especificamente para este trabalho, o papel dos fluxos inter-regionais e sua importância relativa poderão ser verificados.

Do ponto de vista teórico, a discussão sobre os aspectos econômicos do separatismo regional busca identificar custos e benefício da fragmentação geopolítica (Hansen 1978). O arcabouço conceitual pode ser sintetizado em três dimensões principais associadas ao nível de integração econômica da região em questão, da importância das políticas econômicas sistêmicas - determinadas em nível nacional (ou estadual para o caso analisado neste artigo) - e do nível e da estrutura dos sistemas de transferências inter-regionais (Polése 1981). A Tabela 1 apresenta os principais elementos desta discussão.

Esse trabalho se divide em mais quatro partes, além desta introdução. $\mathrm{Na}$ seção 2, faz-se um breve relato sobre as experiências concretas de desmembramento territorial no Brasil, considerando-se os casos recentes de criações de novos Estados e Territórios. A seguir, a seção 3 prossegue com a análise comparativa dos indicadores mencionados, a fim de se evidenciar potenciais diferenças entre a situação atual e a situação futura hipotética. Apresenta-se também a metodologia e os resultados da análise exploratória de dados espa-

\footnotetext{
${ }^{1}$ Projetos de Lei, respectivamente: PDC 120/1995, PDC 439-A/1994, PDC 159/1992, PDC 120/1991, PDC 631/1998, PDC 459/2001, PDC 149/1991
} 

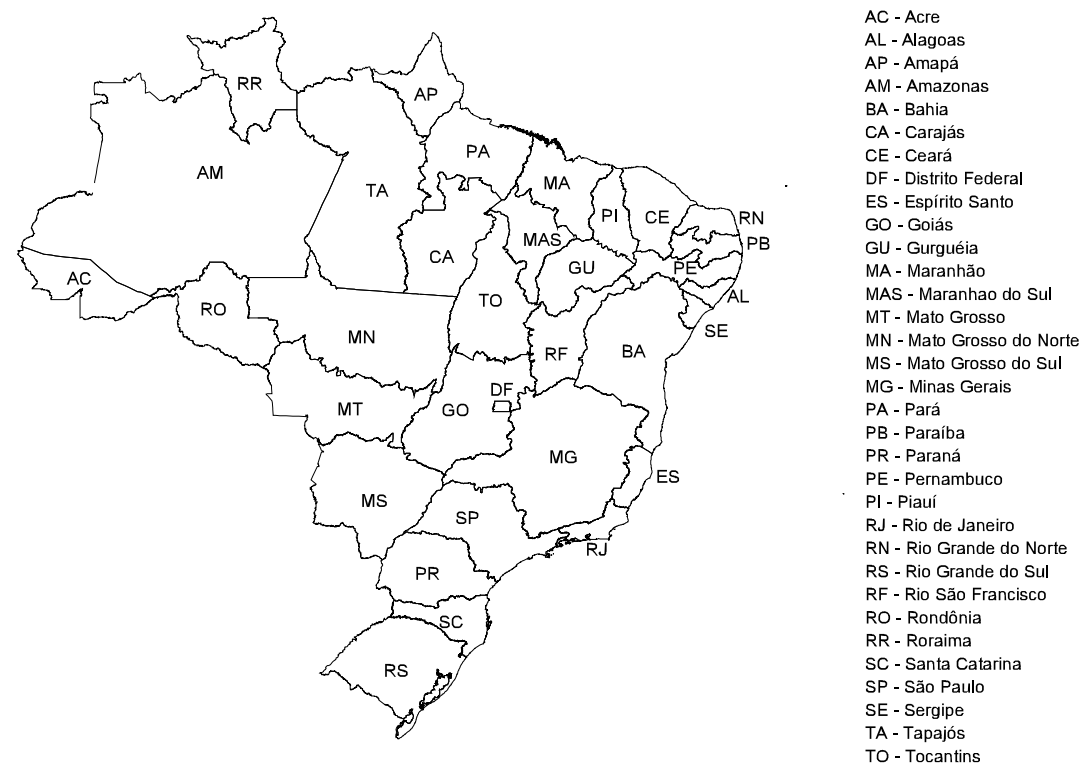

Figura 1: Nova Configuração Geopolítica do Brasil

Tabela 1: Dimensões Econômicas do Separatismo

\begin{tabular}{|c|c|c|c|}
\hline Descrição & $\begin{array}{l}\text { Dimensão 1. Integra- } \\
\text { ção Econômica }\end{array}$ & $\begin{array}{l}\text { Dimensão 2. Políticas } \\
\text { Econômicas Sistêmicas }\end{array}$ & $\begin{array}{l}\text { Dimensão 3. Transfe- } \\
\text { rências Inter-regionais }\end{array}$ \\
\hline Definição & $\begin{array}{l}\text { Ausência de barreiras } \\
\text { institucionais para flu- } \\
\text { xos inter-regionais de } \\
\text { bens e fatores }\end{array}$ & $\begin{array}{l}\text { Políticas e instituições } \\
\text { comuns Podem incluir } \\
\text { vários elementos: polí- } \\
\text { tica fiscal (subsídios, in- } \\
\text { centivos fiscais, investi- } \\
\text { mentos, etc.); política } \\
\text { monetária; marco regu- } \\
\text { latório }\end{array}$ & $\begin{array}{l}\text { Redistribuição inter- } \\
\text { regional dos gastos e } \\
\text { receitas públicas }\end{array}$ \\
\hline $\begin{array}{l}\text { Objetivo Sis- } \\
\text { têmico }\end{array}$ & $\begin{array}{l}\text { Maximização de efici- } \\
\text { ência: integração de } \\
\text { mercados }\end{array}$ & Crescimento econômico & $\begin{array}{l}\text { Equidade: redistribui- } \\
\text { ção de renda }\end{array}$ \\
\hline $\begin{array}{l}\text { Papel do Go- } \\
\text { verno }\end{array}$ & Função reguladora & $\begin{array}{l}\text { Função fiscal e regula- } \\
\text { dora (setorial) }\end{array}$ & Função fiscal \\
\hline $\begin{array}{l}\text { Custos ou } \\
\text { Benefícios da } \\
\text { Separação }\end{array}$ & $\begin{array}{l}\text { Dependem da impor- } \\
\text { tância e da estrutura } \\
\text { dos fluxos de comércio } \\
\text { inter-regional }\end{array}$ & $\begin{array}{l}\text { Dependem da importân- } \\
\text { cia das políticas nacio- } \\
\text { nais/estaduais e de seus } \\
\text { impactos regionais }\end{array}$ & $\begin{array}{l}\text { Dependem do saldo } \\
\text { inter-regional e sua } \\
\text { importância relativa, } \\
\text { bem como da impor- } \\
\text { tância relativa dos } \\
\text { gastos e receitas do } \\
\text { governo central }\end{array}$ \\
\hline
\end{tabular}

Fonte: Adaptado de Polése (1981) 
ciais para cada uma das novas unidades da Federação, comparando-as com os respectivos Estados de origem, de forma a destacar as implicações da heterogeneidade intrarregional subjacente para a lógica das políticas públicas dos novos Governos Estaduais. Na seção 4, descreve-se, por sua vez, a metodologia de insumo-produto, com enfoque no método de extração, e apresentam-se os resultados que permitirão avaliar a importância relativa de cada um dos novos Estados no novo contexto federativo. Na seção 5 são descritos os resultados de simulações da estrutura das transferências governamentais (FPM e FPE) no novo contexto federativo. Por fim, apresentam-se as considerações finais.

\section{Histórico Recente da Fragmentação Geopolítica Nacional}

No fim da década de 1980, o Brasil saía de uma ditadura militar que durara mais de 20 anos. Assim como as demais experiências internacionais, o histórico de concentração estatal no País fez com que a Assembleia Constituinte de 1986 levasse consigo certa aversão a qualquer ideia centralizadora. Dessa forma, a elaboração da nova Constituição de 1988 reacendeu o debate políticoeconômico da questão federativa no Brasil.

Como apontado por Souza $(1998,2001)$ e Affonso (1994), no Brasil ocorre um federalismo "às avessas", pois diferentemente do padrão dos Estados Unidos, em que as unidades da Federação, com diferentes ideologias, se uniram para formar um país (Estado), no Brasil o Estado, para garantir a continuação da agenda política vigente, decidiu pela federalização brasileira.

A Constituição Brasileira de 1988 não modificou esse caráter, visto o Art. $1{ }^{\circ}$ considera que "a República Federativa do Brasil será formada pela união indissolúvel dos Estados e Municípios e do Distrito Federal", sendo que apenas o Art. 25 irá apontar que "os Estados organizam-se e regem-se pelas Constituições e leis que adotarem, observados os princípios desta Constituição". Apesar de uma criação "artificial", o federalismo no Brasil passou por diferentes regimes e conseguiu sobreviver (Souza 2001).

Serra \& Afonso (1999) fazem um breve histórico dessas mudanças como a alternância entre períodos de descentralização — durante a República Velha e o Pós-Segunda Guerra - e períodos de centralização - como na Era Vargas e na Ditadura Militar de 1964-1988. Essas mudanças, entretanto, não se deram de maneira geral no caráter territorial, mas tiveram foco na estrutura fiscal do País.

A criação de novos Estados está determinada no Art. 18 da Constituição, em seu parágrafo $3^{\circ}$, tal que: "os Estados podem incorporar-se entre si, subdividir-se ou desmembrar-se para se anexarem a outros, ou formarem novos Estados ou Territórios Federais, mediante aprovação da população diretamente interessada, através de plebiscito, e do Congresso Nacional, por lei complementar."

No foco do debate sobre o federalismo no Brasil, três pontos se destacam: (i) a questão fiscal; (ii) a representação na Assembleia; e (iii) o aumento da máquina estatal. O primeiro ponto é importante, pois, como extensivamente discutido por Serra \& Afonso (1999), Souza (1998) e Affonso (1994, 2000), com a descentralização do governo, os Estados passam a ter maior importância, principalmente na arrecadação tributária e gastos sociais. Porém, não sai da pauta nacional a questão da desigualdade regional no País, sendo que os 
Fundos de Participação, que representam os repasses do Governo Federal para a esfera estadual, têm importante papel a ser cumprido, tal que os Estados que menos arrecadam são os que recebem maiores participações.

Outro ponto envolvendo a questão tributária é a guerra fiscal. Dada a perda da importância vertical do sistema federativo para uma orientação mais horizontal, os Estados passam a ter o controle dos impostos de maneira tal que, para garantir seu desenvolvimento econômico, ocorrem movimentos de redução das alíquotas tributárias para atração de diferentes atividades econômicas (Serra \& Afonso 1999, Souza 1998, Affonso 1994, 2000).

A questão da representação também é de grande interesse quando se discute o aumento do número de Estados. A Constituição de 1988 em seus Artigos 45 e 46 define que o número de deputados de cada Estado será proporcional à população, não podendo ser menor que oito e nem maior que setenta deputados, enquanto cada Estado terá três senadores. Essa divisão faz com que Estados com populações maiores percam importância relativa no Congresso. Souza (1998) evidencia que o Sudeste possuía 46\% do eleitorado, porém apenas $33,6 \%$ de representação.

O aumento dos custos da máquina estatal pode ser visto como consequência imediata da fragmentação geopolítica, uma vez que, por um lado, o aumento no número deputados e senadores gera aumentos diretos e indiretos no âmbito do Legislativo, e, por outro lado, os novos Estados devem estruturar-se com a criação de esferas executiva, legislativa e judiciária próprias, o que também levaria ao aumento das despesas governamentais para sua sustentação.

Para entender a atual divisão do território brasileiro, pode-se remeter ao Governo de Getúlio Vargas com os desmembramentos dos atuais estados do Acre, Rondônia, Roraima e Amapá. ${ }^{2}$ Com a construção de Brasília e a transferência do Distrito Federal para o Centro-Oeste em 1960, o antigo Distrito Federal foi elevado à categoria de Estado, formando assim o Estado da Guanabara, que era composto pelo município do Rio de Janeiro e sua área rural.

Na década de 1970, o Estado da Guanabara foi incorporado ao Estado do Rio de Janeiro. Os territórios do Acre e Rondônia foram elevados à categoria de Estados ainda durante a ditadura militar, sendo que Roraima e Amapá, apenas na constituição de 1988. A Constituição de 1988 ainda desmembrou o território do Estado de Goiás em dois, tal que a porção norte do Estado formasse o atual Estado de Tocantins.

\section{Análise Exploratória de Indicadores Socioeconômicos}

Esta seção realiza a análise exploratória de alguns indicadores socioeconômicos (PIB, PIB per capita e IFDM) para os territórios desmembrados. Todos os indicadores foram obtidos, inicialmente, a partir de informações em nível municipal, e agregados, posteriormente, em nível estadual. O objetivo desta seção é contextualizar as economias das novas unidades da Federação no Brasil.

\footnotetext{
${ }^{2}$ Outros territórios foram desmembrados, mas após a Segunda Guerra voltaram à sua condição original.
} 


\subsection{Contexto Interestadual}

Para fins de análise da posição relativa dos novos Estados, consideramos dois bancos de dados. O primeiro refere-se aos indicadores no contexto federativo atual, com os 26 Estados e o Distrito Federal. O segundo considera as novas propostas de configuração geopolítica do País, considerando 32 Estados e o Distrito Federal. A apresentação cartográfica dos indicadores nas figuras subsequentes mantém sempre, para os dois bancos de dados, a mesma estrutura de quebras naturais nas legendas.
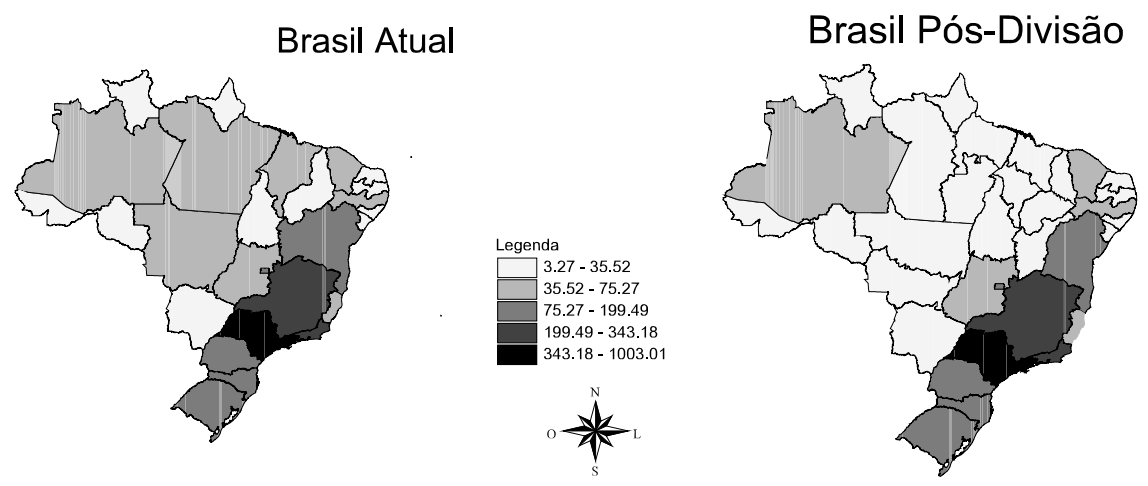

Figura 2: Comparação do PIB - Brasil versus Brasil "Novo"

A Figura 2 apresenta os resultados para o PIB. Como esperado, os Estados a serem divididos perderiam importância relativa no cenário nacional, já que passariam a ter uma menor participação no PIB nacional. O caso da Bahia se destaca, pois, apesar da divisão, ele se manteria na mesma faixa que anteriormente, o que pode ser explicado pelo fato de que o PIB da região desmembrada, apesar de constituir importante participação no PIB do Estado, é concentrado principalmente na atividade agrícola.

A Figura 3, por sua vez, apresenta a espacialização do PIB per capita. Como é possível notar, o padrão observado atualmente manter-se-ia com as divisões estaduais. Os Estados do Maranhão e Piauí, que já se encontram na faixa mais baixa de PIB per capita, manter-se-iam nos níveis mais baixos. A Bahia e o Mato Grosso manter-se-iam também na mesma faixa em que se encontram atualmente, porém essa manutenção se difere do caso dos outros Estados, já que os novos Estados possuiriam um PIB relativamente alto e uma densidade populacional relativamente baixa, dado que são regiões essencialmente voltadas para o agronegócio.

O Estado do Pará, por sua vez, é o que apresentaria maior discrepância com a separação. O Estado encontra-se, atualmente, na segunda faixa de PIB per capita. Com a divisão, os Estados do Tapajós e do Pará teriam um PIB per capita inferior ao do PIB per capita do atual Estado do Pará, enquanto o PIB per capita do Estado de Carajás passaria para uma categoria superior, evidenciando uma fonte de diferenças regionais atualmente.

A Figura 4 apresenta o IFDM (Índice FIRJAN de Desenvolvimento Municipal) para os Estados. O IFDM é calculado somente para municípios, e sua agregação estadual teve como base a participação populacional do município na população estadual. O índice segue a ideia do IDH, sendo referência como indicador socioeconômico amplo. Como é possível perceber, o único caso em 

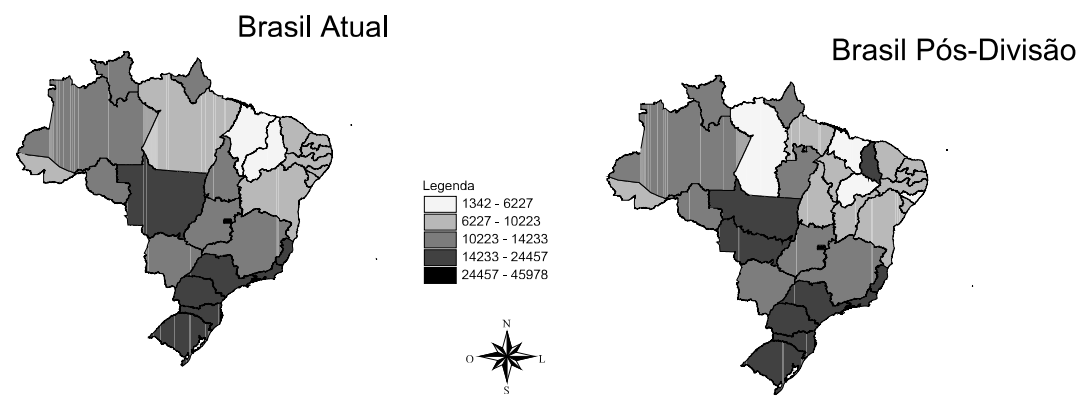

Figura 3: Comparação do PIB per Capita - Brasil versus Brasil "Novo"

que os Estados desmembrados permaneceriam na mesma faixa que o Estado atual de origem seria o caso do Maranhão.

No caso do atual Estado do Pará, o Estado de Tapajós passaria a apresentar um índice de desenvolvimento menor que o do Estado atual, enquanto os Estados do Pará (desmembrado) e Carajás permaneceriam na mesma faixa de desenvolvimento. Os Estados de Mato Grosso e Bahia, quando desmembrados, permaneceriam como os respectivos Estados atuais, mantendo seu índice de desenvolvimento na mesma faixa de variação, enquanto os demais entes desmembrados cairiam uma faixa. O Piauí, por sua vez, apresenta uma situação diferente das demais, sendo que o Estado desmembrado equiparado ao atual teria seu índice aumentado, enquanto o novo Estado cai uma faixa.
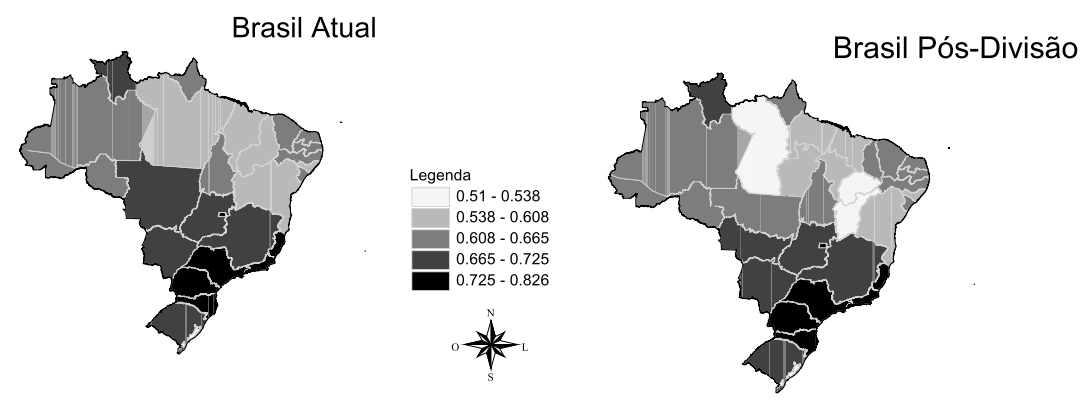

Figura 4: Comparação do IFDM — Brasil versus Brasil "Novo"

Por meio da análise das Figuras anteriores e da Tabela 2, pode-se concluir que os Estados criados seriam os que apresentariam, em geral, menor PIB, menor PIB per capita e menor IFDM. Dessa forma, as regiões criadas constituiriam essencialmente regiões mais pobres e que dependeriam de maneira mais forte de auxílio governamental nos períodos de transição nos próximos anos.

\subsection{Contexto Intraestadual}

Uma pergunta, entretanto, que merece destaque é: haveria alguma lógica econômica nas divisões propostas? Ou haveria apenas um critério eminentemente político para essas novas configurações fronteiriças? Para endereçar de forma preliminar essa questão, buscou-se analisar, por meio de técnicas de análise exploratória de dados espaciais (AEDE), o padrão espacial dos indicadores previamente analisados de tal forma que a verificação dos padrões 
Tabela 2: Ranking dos Estados por Indicador

\begin{tabular}{|c|c|c|c|c|c|c|c|}
\hline \multirow{2}{*}{ Estados Atuais } & \multirow{2}{*}{$\begin{array}{l}\text { Estados } \\
\text { Desmembrados }\end{array}$} & \multicolumn{3}{|c|}{ Ranking Atualmente } & \multicolumn{3}{|c|}{ Ranking Pós Divisão } \\
\hline & & PIB & PPC & IFDM & PIB & PPC & IFDM \\
\hline Rondônia & & 22 & 13 & 18 & 22 & 15 & 19 \\
\hline Acre & & 26 & 18 & 17 & 30 & 19 & 18 \\
\hline Amazonas & & 15 & 11 & 20 & 13 & 12 & 21 \\
\hline Roraima & & 27 & 14 & 12 & 32 & 16 & 12 \\
\hline \multirow[t]{4}{*}{ Pará } & & 13 & 22 & 25 & - & - & - \\
\hline & Tapajós & - & - & - & 31 & 31 & 31 \\
\hline & Pará & - & - & - & 14 & 26 & 25 \\
\hline & Carajás & - & - & - & 24 & 13 & 28 \\
\hline Amapá & & 25 & 15 & 19 & 29 & 17 & 20 \\
\hline Tocantins & & 24 & 16 & 21 & 26 & 8 & 23 \\
\hline \multirow[t]{3}{*}{ Maranhão } & & 16 & 26 & 27 & - & - & - \\
\hline & Maranhão & - & - & - & 17 & 30 & 29 \\
\hline & Maranhão do Sul & - & - & - & 27 & 25 & 30 \\
\hline \multirow[t]{3}{*}{ Piauí } & & 23 & 17 & 23 & - & - & - \\
\hline & Piauí & - & - & - & 25 & 32 & 22 \\
\hline & Gurguéia & - & - & - & 33 & 33 & 32 \\
\hline Ceará & & 12 & 23 & 14 & 12 & 27 & 15 \\
\hline Rio Grande do Norte & & 19 & 20 & 13 & 19 & 23 & 13 \\
\hline Paraíba & & 18 & 24 & 22 & 18 & 28 & 24 \\
\hline Pernambuco & & 10 & 21 & 15 & 10 & 24 & 16 \\
\hline Alagoas & & 21 & 25 & 24 & 21 & 29 & 26 \\
\hline Sergipe & & 20 & 18 & 16 & 20 & 20 & 17 \\
\hline \multirow[t]{3}{*}{ Bahia } & & 7 & 19 & 26 & - & - & - \\
\hline & Rio São Francisco & - & - & - & 28 & 21 & 33 \\
\hline & Bahia & - & - & - & 8 & 22 & 27 \\
\hline Minas Gerais & & 3 & 9 & 9 & 3 & 10 & 9 \\
\hline Espírito Santo & & 11 & 5 & 6 & 11 & 5 & 6 \\
\hline Rio de Janeiro & & 2 & 3 & 3 & 2 & 3 & 3 \\
\hline São Paulo & & 1 & 2 & 1 & 1 & 2 & 1 \\
\hline Paraná & & 5 & 8 & 4 & 5 & 9 & 4 \\
\hline Santa Catarina & & 6 & 4 & 5 & 6 & 4 & 5 \\
\hline Rio Grande do Sul & & 4 & 6 & 7 & 4 & 6 & 7 \\
\hline Mato Grosso do Sul & & 17 & 10 & 8 & 16 & 11 & 8 \\
\hline \multirow[t]{3}{*}{ Mato Grosso } & & 14 & 7 & 11 & - & - & - \\
\hline & $\begin{array}{l}\text { Mato Grosso do } \\
\text { Norte }\end{array}$ & - & - & - & 23 & 8 & 14 \\
\hline & Mato Grosso & - & - & - & 15 & 7 & 11 \\
\hline Goiás & & 9 & 12 & 10 & 9 & 14 & 10 \\
\hline Distrito Federal & & 8 & 1 & 2 & 7 & 1 & 2 \\
\hline
\end{tabular}

Fonte: Elaboração Própria. 
espaciais existentes indicaria a presença de um tipo de lógica econômica utilizada para essas divisões.

\section{Análise Exploratória de Dados Espaciais (AEDE)}

Para se analisar o padrão espacial de uma variável, é aconselhado que seja feita uma análise com as estatísticas LISA (Local Indicators of Spatial Association), que são quaisquer estatísticas que satisfaçam a dois critérios, a saber: a) trazer para cada observação, indicação de agrupamento espacial significante de valores similares ao redor dessa observação; b) a soma dos LISAs para todas as observações é proporcional ao indicador global de associação espacial (Anselin 1995).

Anselin (1995) define o I de Moran Local, uma das LISAs mais utilizadas, como:

$$
I_{i}=z_{i} * \sum_{j} w_{i j} z_{j}
$$

onde:

$I_{i}$ é o I de Moran Local;

$z_{i}$ e $z_{j}$ são os desvios em relação à média;

$w_{i j}$ são os elementos da matriz de pesos espaciais.

O I de Moran Local pode assumir valores positivos ou negativos. No primeiro caso, pode-se afirmar que existe uma aglomeração espacial de valores similares, enquanto no segundo, existe uma aglomeração espacial de valores distintos.

A matriz $W$ de vizinhos pode ser definida de diferentes maneiras, como matrizes socioeconômicas, contiguidade, distância, entre outras. ${ }^{3}$ Será utilizada, neste artigo, a ideia de $k$ vizinhos mais próximos, que pode ser definida, segundo Almeida (2010) como:

$$
\begin{cases}w_{i j}(k)=0 & \text { se } i=j \\ w_{i j}(k)=1 & \text { se } d_{i j}=D_{i}(k) \text { e } \frac{w_{i j}(k)}{\sum_{j} w_{i j}} \text { para } k=1,2, \ldots, n \\ w_{i j}(k)=0 & \text { se } d_{i j}>D_{i}(k)\end{cases}
$$

\section{Resultados}

O padrão espacial foi analisado a partir do I de Moran local para cada uma das variáveis - PIB, PIB per capita e IFDM - tal que as matrizes de pesos espaciais utilizadas buscaram captar a maior dependência espacial possível, ou seja, foi utilizada aquela que maximizava o I de Moran. No caso dos Estados separados, foi elaborada uma matriz para cada um, individualmente. A seguir, foram calculadas as estatísticas I de Moran local separadamente, sendo, porém, apresentadas em conjunto a fim de facilitar as comparações.

Analisando primeiramente o Estado do Pará, é possível notar algumas mudanças com e sem o desmembramento do Estado. Observando-se a Figura 5, nota-se que o padrão verificado atualmente é mantido, porém, novos municípios passam a ser significantes estatisticamente.

\footnotetext{
${ }^{3}$ Para mais detalhes ver Almeida $(2010)$
} 


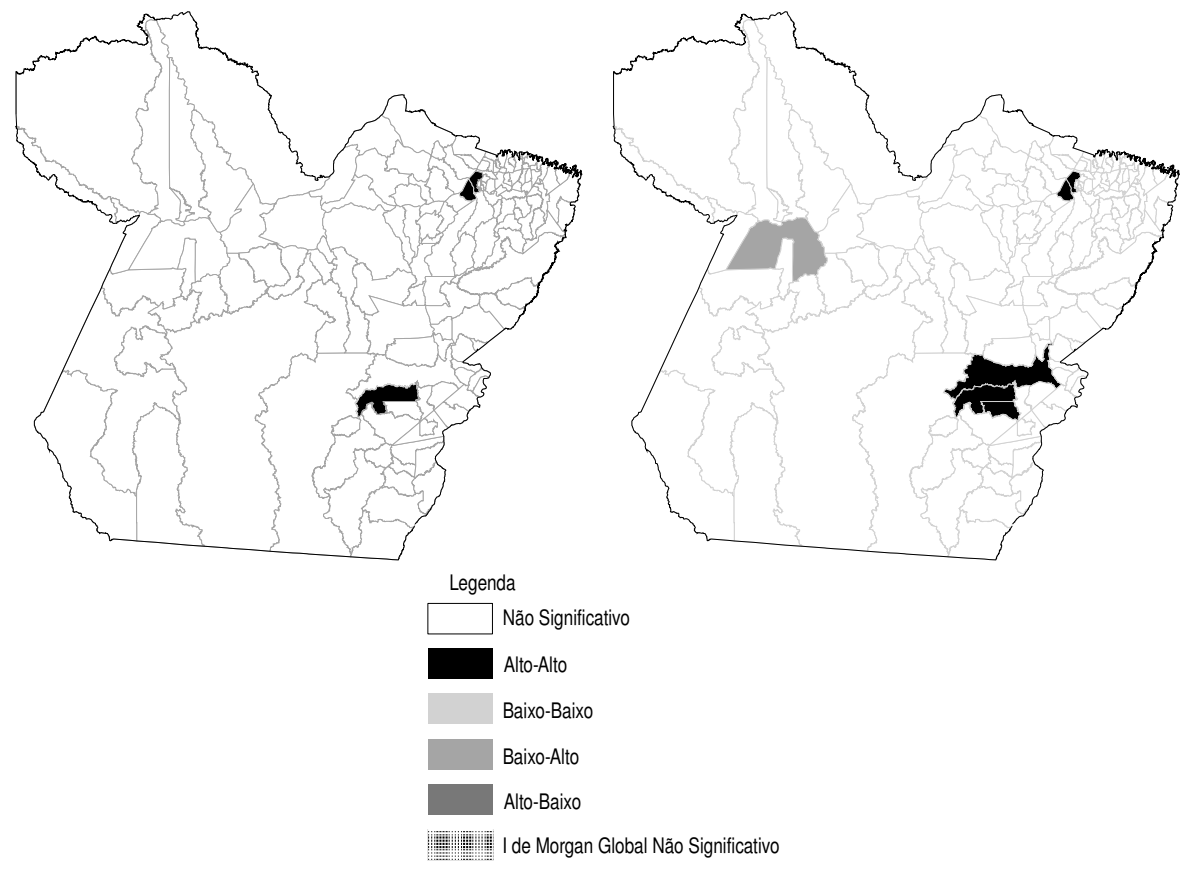

Figura 5: Comparação do Padrão Espacial do PIB — Pará

As Figuras 6 e 7 apresentam um fenômeno interessante, e que será discutido mais adiante. Em ambas as Figuras, o que se percebe é que, se atualmente existem evidências de que haja um padrão espacial para as variáveis em análise, com a separação isso não ocorreria nos dois casos para o Estado de Tapajós e no caso do PIB per capita para o Estado do Pará.

Entretanto, nas duas Figuras ainda é notável que os clusters espaciais existentes atualmente seriam mantidos, sendo que, mais especificamente para a variável IFDM, no caso do Estado do Pará pós-divisão, diminuem-se os casos de clusters Baixo-Baixo. Esses clusters passariam a ser observados no que seria o Estado de Carajás.

O Maranhão (Figuras 8 e 9) e o Piauí (Figuras 10 e 11) não apresentaram padrões espaciais para o PIB nem com a configuração atual e nem com as divisões propostas. Para as variáveis analisadas no Maranhão, nota-se que o padrão verificado ao sul do Estado seria mantido, porém, com a separação, a estrutura espacial do PIB per capita alterar-se-ia ao norte do Estado atual, no "novo" Estado do Maranhão. A análise do IFDM, por sua vez, revela o contrário do padrão para o PIB per capita, sendo que o padrão observado ao norte do Estado atual seria mantido e haveria uma perda de significância estatística nos municípios ao sul, mudando assim o padrão espacial no Estado a ser criado.

Para o Piauí, a AEDE revela que, para o PIB per capita, a divisão do Estado iria alterar o padrão espacial existente, tal que municípios ao sul perderiam significância, enquanto municípios ao norte do Estado atual passariam a ter maior importância.

Para o IFDM, entretanto, assim como no caso do Pará, a mudança passaria a ser mais radical, no sentido de que, se antes existia um padrão espacial para todo o Estado atual, o novo Estado a ser criado não apresentaria nenhum, 


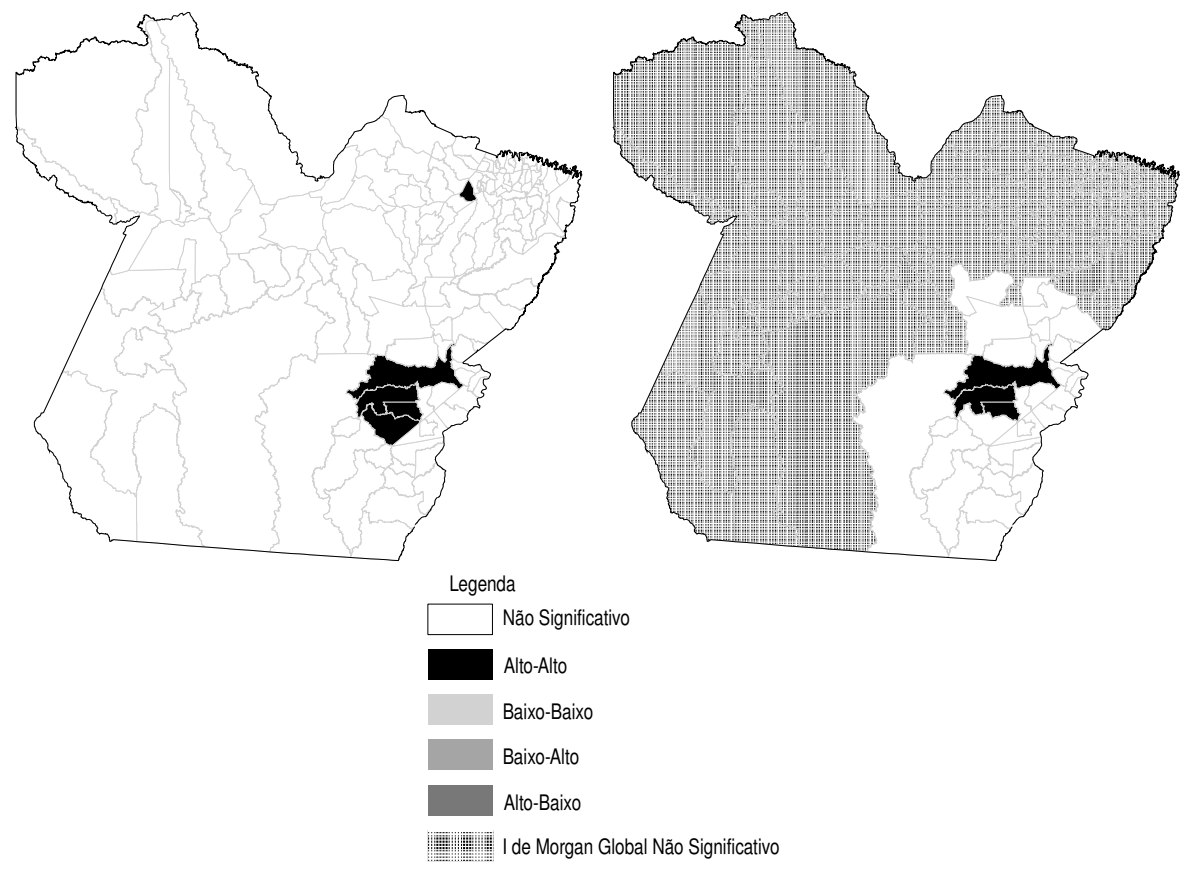

Figura 6: Comparação do Padrão Espacial do PIB per Capita — Pará

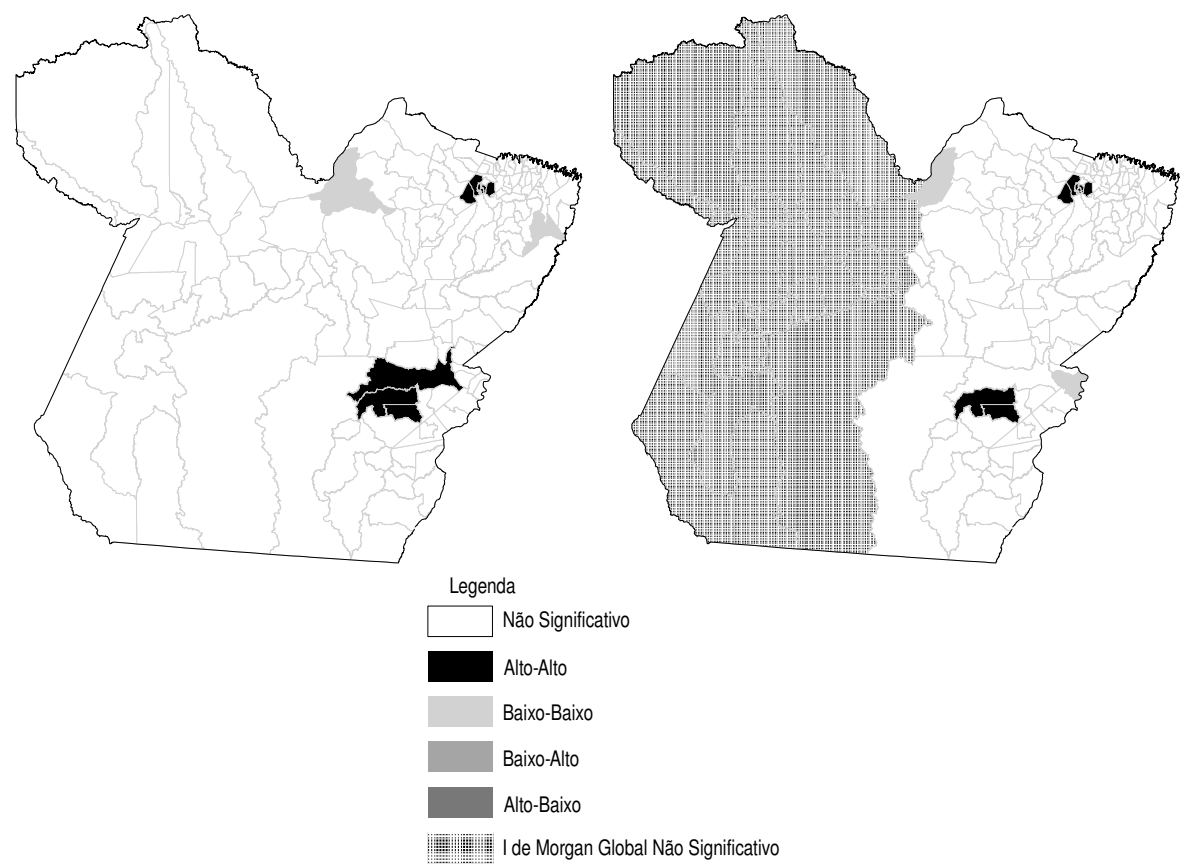

Figura 7: Comparação do Padrão Espacial do IFDM — Pará 


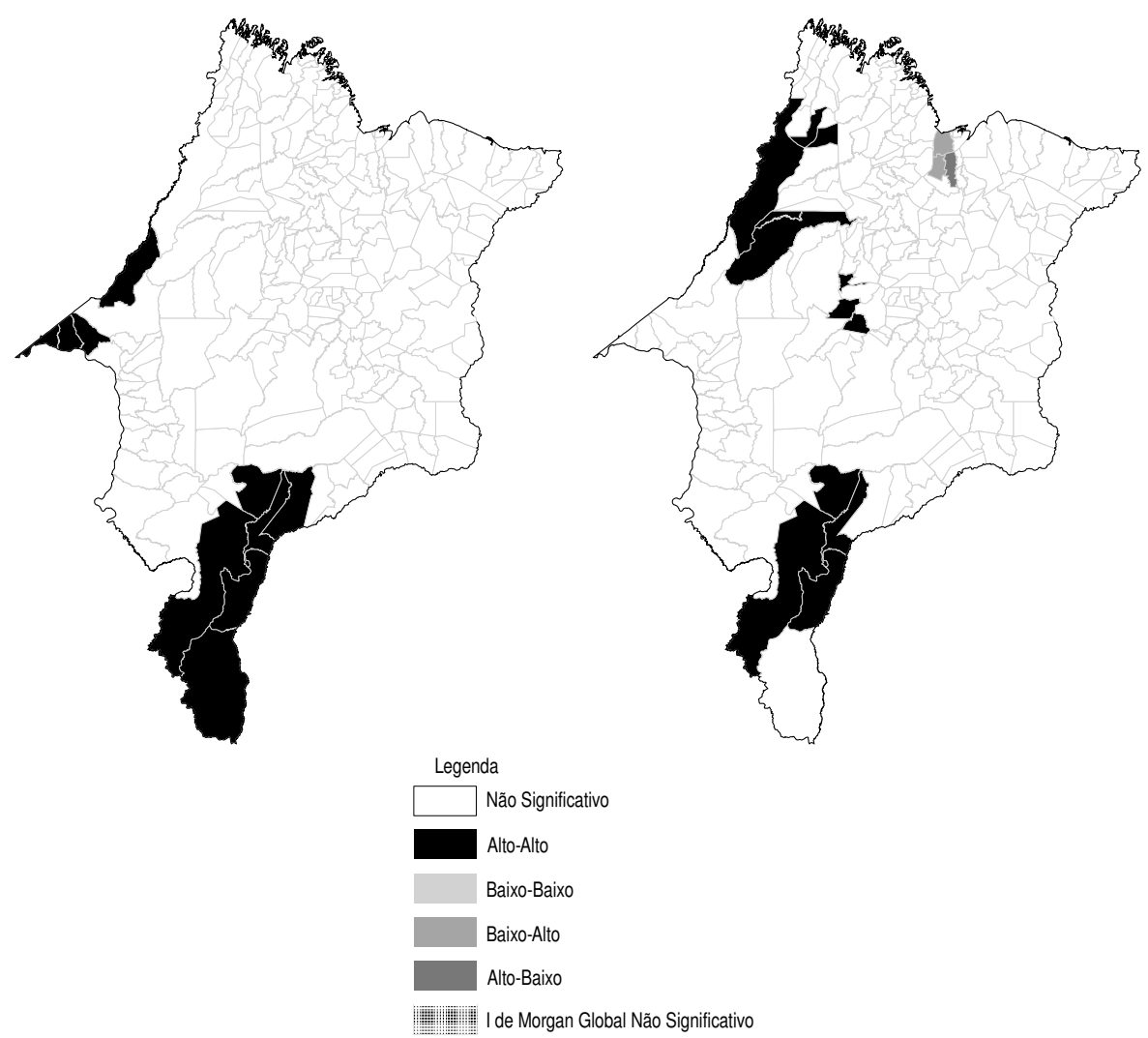

Figura 8: Comparação do Padrão Espacial do PIB per Capita — Maranhão

e o padrão no "novo" Estado do Piauí seria diferente daquele apresentado atualmente.

As Figuras 12 a 14 apresentam o padrão espacial das variáveis analisadas para os municípios da Bahia. Como é possível notar, em geral há a manutenção da existência de um padrão espacial. A análise do PIB é a que apresenta a maior diferença, já que os municípios no extremo oeste do atual Estado, que antes não eram significantes, passariam a ter um papel mais importante no "novo" Estado.

Como se percebe, o PIB per capita, com e sem divisão, apresenta o mesmo padrão e há variações marginais quando analisado o IFDM, com aumento na importância dos municípios em geral.

Voltando-se para o Estado do Mato Grosso, a variável que apresenta maior mudança no padrão espacial é o PIB (Figura 15). Como é possível notar, atualmente há um padrão que está concentrado mais ao sul, porção territorial que constituiria o "novo" Estado do Mato Grosso. Porém, com a divisão, esse "novo" Estado passaria a apresentar aleatoriedade espacial do PIB, ou seja, nenhum padrão espacial global seria detectado. Já o Estado do Mato Grosso do Norte, que na configuração atual do Estado não apresenta qualquer padrão, ou seja, não há significância estatística, ao ser dividido passaria a ter um cluster de municípios de alto valor de PIB cercado por municípios de alto valor de PIB, localizado ao centro-sul deste "novo" Estado.

A análise do PIB per capita e do IFDM por sua vez evidenciam que o pa- 


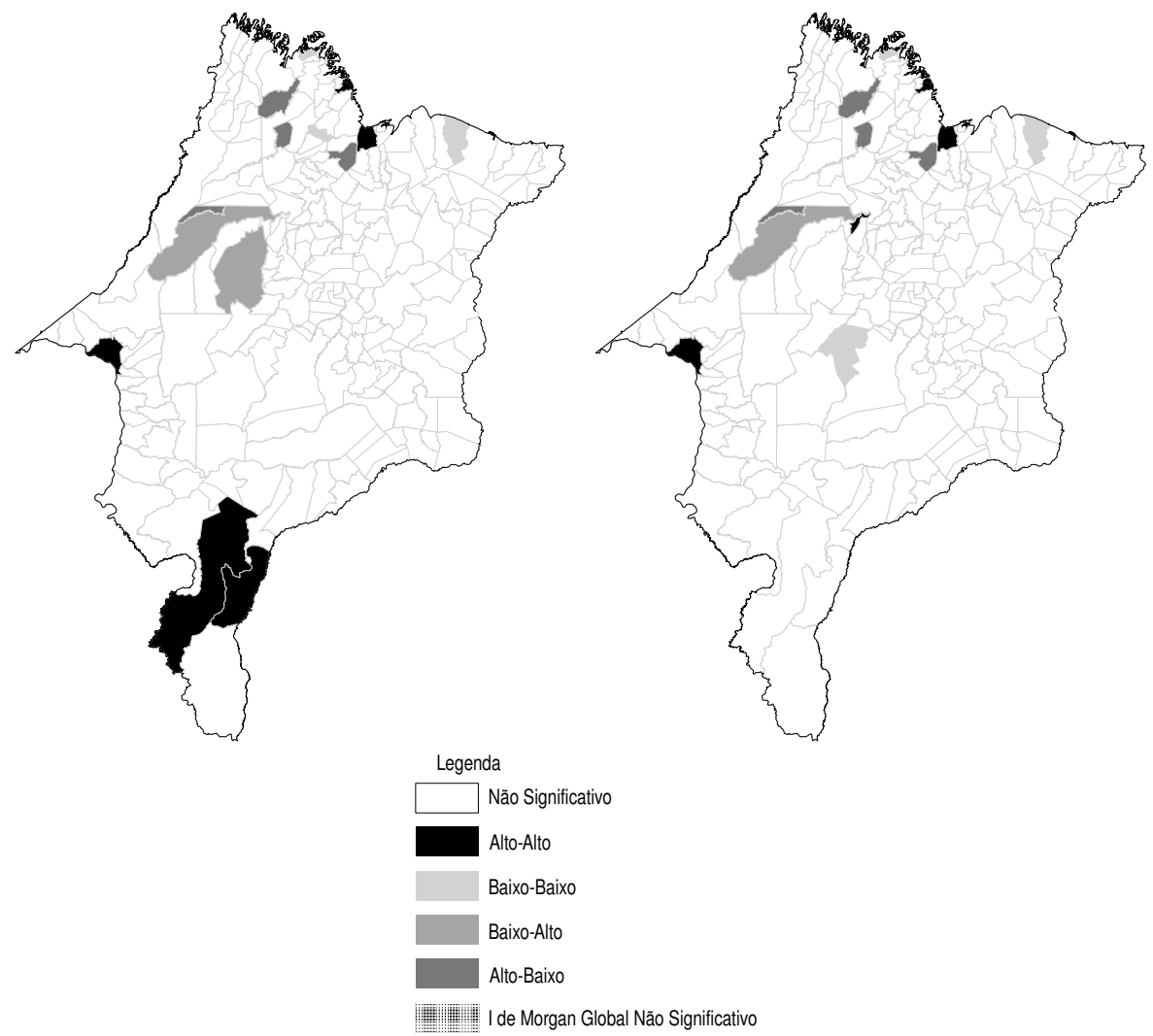

Figura 9: Comparação do Padrão Espacial do IFDM — Maranhão

drão espacial verificado atualmente seria mantido com a divisão com apenas algumas mudanças marginais quanto à significância dos municípios, tal que não se verificam inversões nos padrões apresentados. Destaca-se, porém, a região central do Estado atual que, com a divisão, passaria a apresentar um padrão mais distinto, e os municípios ao extremo sul, que passariam a ser significativos.

O índice de Moran local não significativo nas novas regiões, ou seja, a ideia de que as variáveis estariam aleatoriamente distribuídas nos novos Estados, o que não ocorria anteriormente, é um indício de que não há evidência de uma lógica espacial hierárquica na definição das novas fronteiras.

No futuro, a definição dessas fronteiras em um subespaço econômico em relação ao original restringe a alocação de recursos, principalmente de recursos públicos, induzindo a formação de um processo socioeconômico "não aleatório" do ponto de vista espacial. Os novos limites geopolíticos eventualmente definirão ações econômicas, circunscritas em espaços economicamente artificiais associados a uma nova hierarquia espacial com novas restrições fronteiriças.

Um exemplo são os serviços públicos estaduais, que tendem a apresentar um padrão de especialização cada vez maior nas áreas urbanas hierarquicamente superiores. As novas capitais terão um papel de polarização fundamental na configuração da nova territorialidade dos entes federativos a serem criados. 


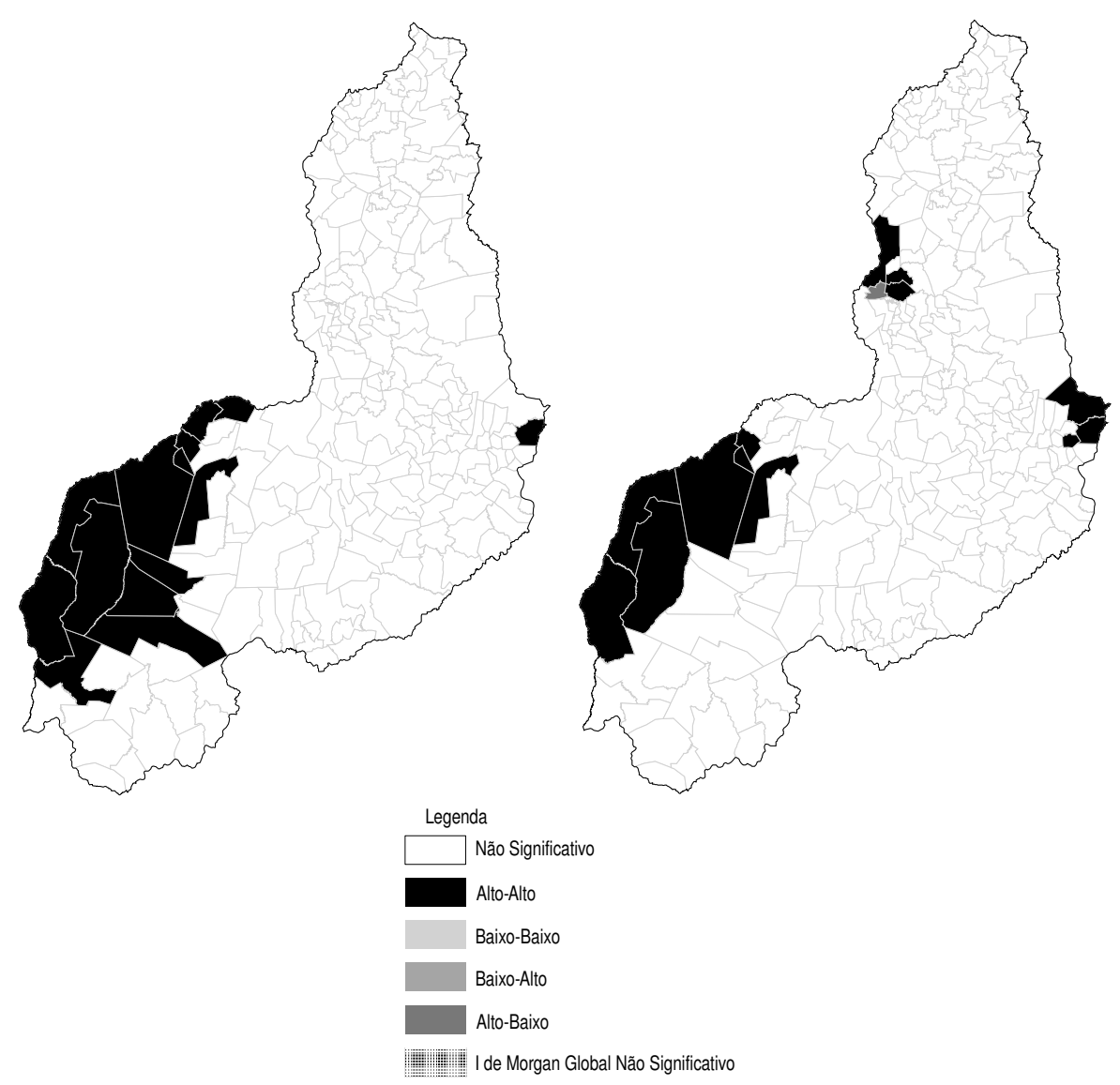

Figura 10: Comparação do Padrão Espacial do PIB per Capita — Piaúí

A segmentação do espaço geopolítico atual a partir da criação dos novos Estados definirá artificialmente novos condicionantes espaciais que reorientarão os papéis das principais áreas urbanas, principalmente nos espaços onde não se encontram as atuais capitais. O processo orçamentário amplo exigirá novas posturas de municípios antes acomodados com sinais emitidos pelos governos estaduais a partir das capitais originais.

\section{Contribuição Produtiva das Novas Unidades da Federação}

\subsection{Método de Extração}

Considere $^{4}$ o caso geral de um modelo de insumo-produto inter-regional com $N$ regiões e $n$ setores produtivos em cada região. ${ }^{5}$ O modelo é dado por:

$$
x=A x+f
$$

onde:

$x$ - é o vetor coluna de produto com $n N$-elementos.

\footnotetext{
${ }^{4}$ Esta seção está baseada em Dietzenbacher et al. (1993)

${ }^{5}$ As regiões serão representadas por sobrescritos $I, J=1, \ldots N$ e os setores por subescritos $i, j=$ $1, \ldots n$.
} 


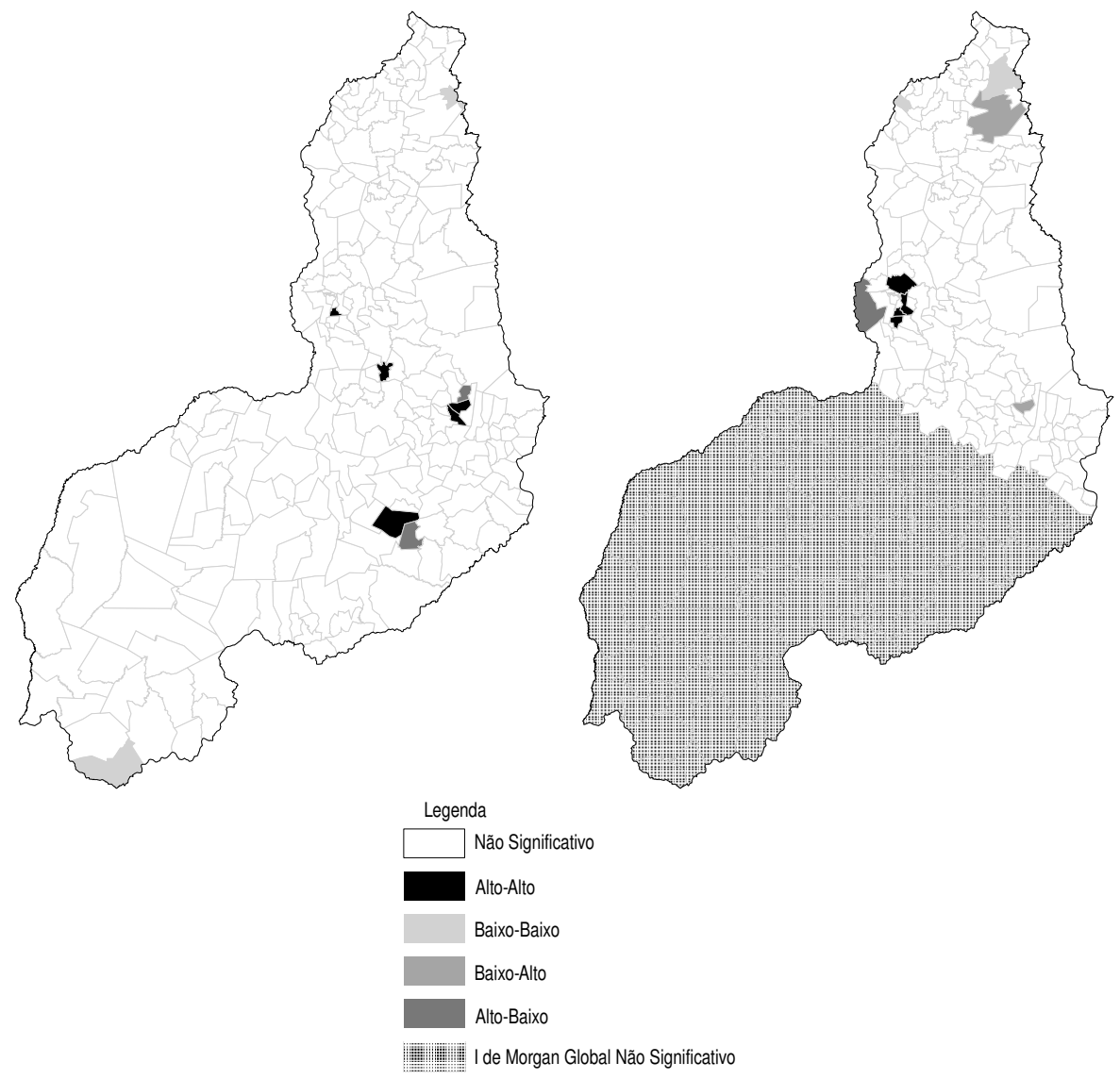

Figura 11: Comparação do Padrão Espacial do IFDM — Piauí

$A$ - é a matriz $(n N \times n N)$ de coeficientes dos insumos.

$f$ - é o vetor coluna de demanda final com $n N$-elementos.

A solução da equação (3) será:

$$
x=(I-A)^{-1} f \text { ou } B f
$$

onde $B=(I-A)^{-1}$ é a inversa de Leontief

O vetor de produto é particionado da seguinte maneira. ${ }^{6}$

$$
x=\left(x^{1^{\prime}}, \cdots, x^{I^{\prime}}, \cdots, x^{N^{\prime}}\right)
$$

onde $x^{I}=\left(x_{1}^{I}, \cdots, x_{i}^{I}, \cdots, x_{n}^{I}\right)$

A matriz de coeficientes é construída da seguinte forma:

$$
A=\left[\begin{array}{ccc}
A^{11} & \cdots & A^{1 N} \\
\vdots & \ddots & \vdots \\
A^{N 1} & \cdots & A^{N N}
\end{array}\right]
$$

\footnotetext{
${ }^{6} \mathrm{O}$ vetor $f$ pode ser particionado da mesma forma
} 


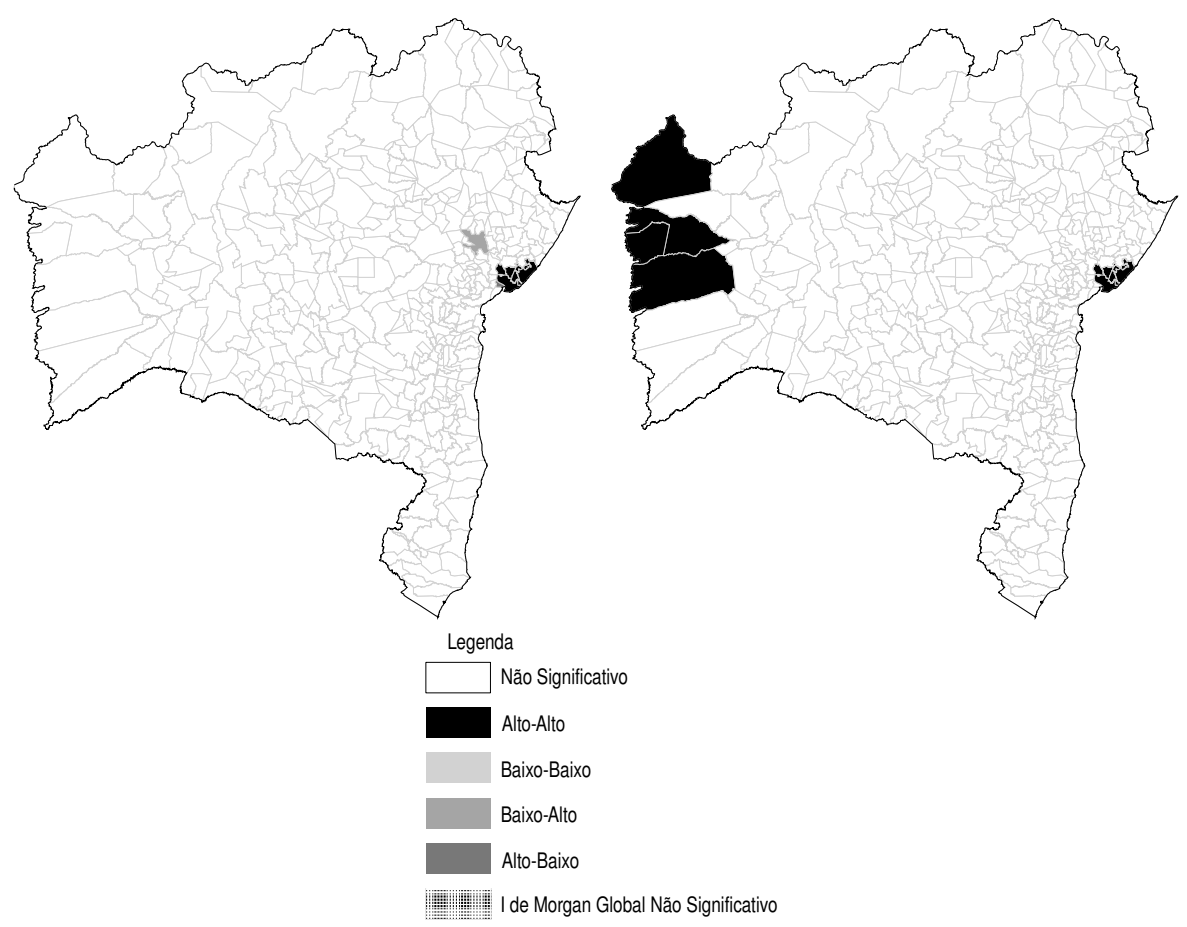

Figura 12: Comparação do Padrão Espacial do PIB — Bahia

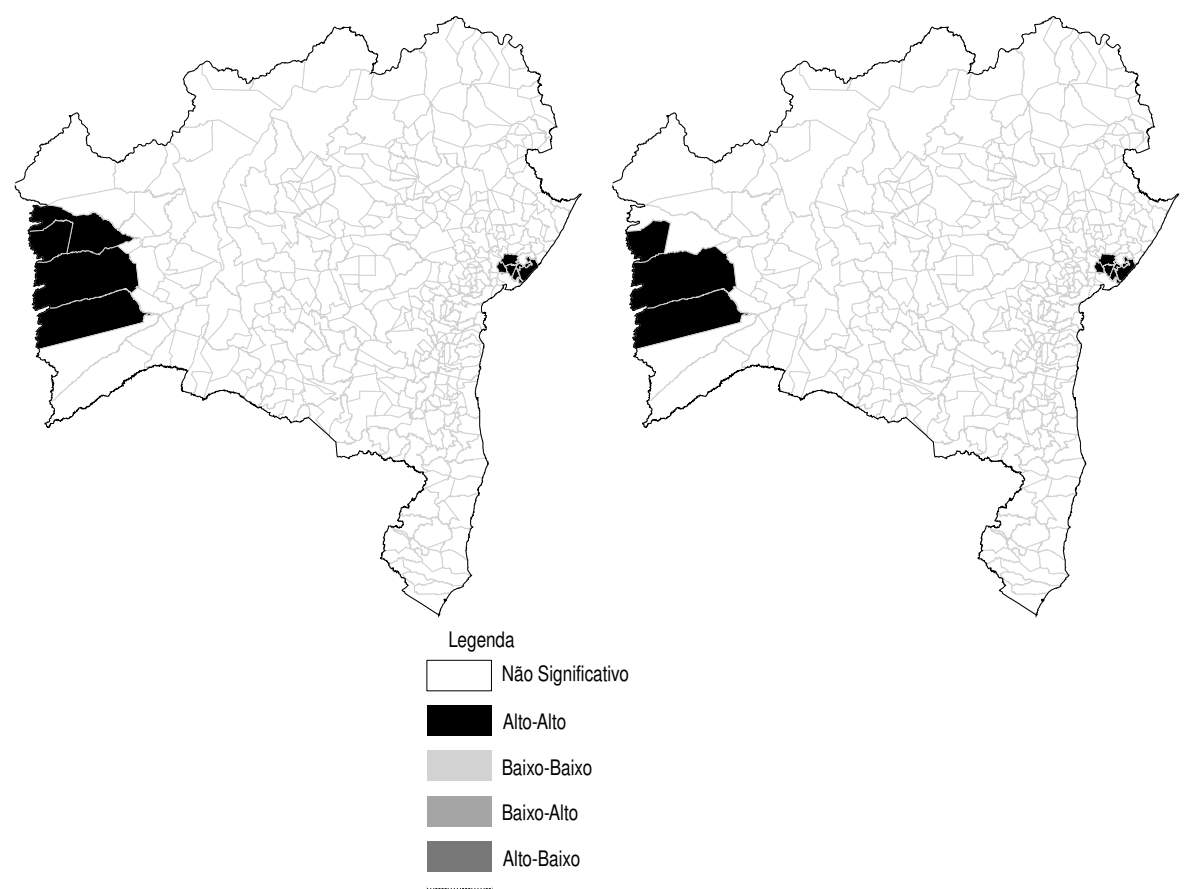

1.:-IIIII I Morgan Global Não Significativo

Figura 13: Comparação do Padrão Espacial do PIB per Capita — Bahia 


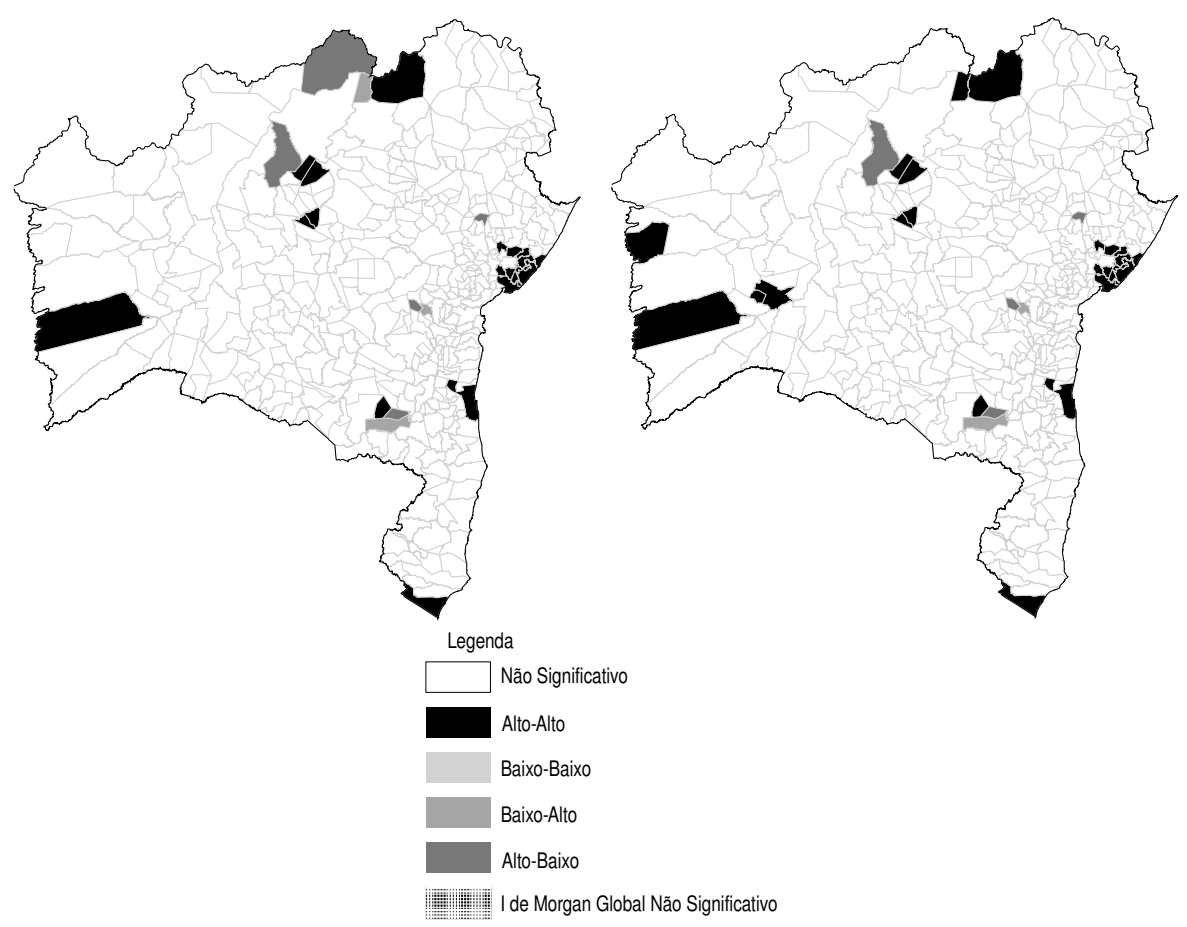

Figura 14: Comparação do Padrão Espacial do IFDM — Bahia

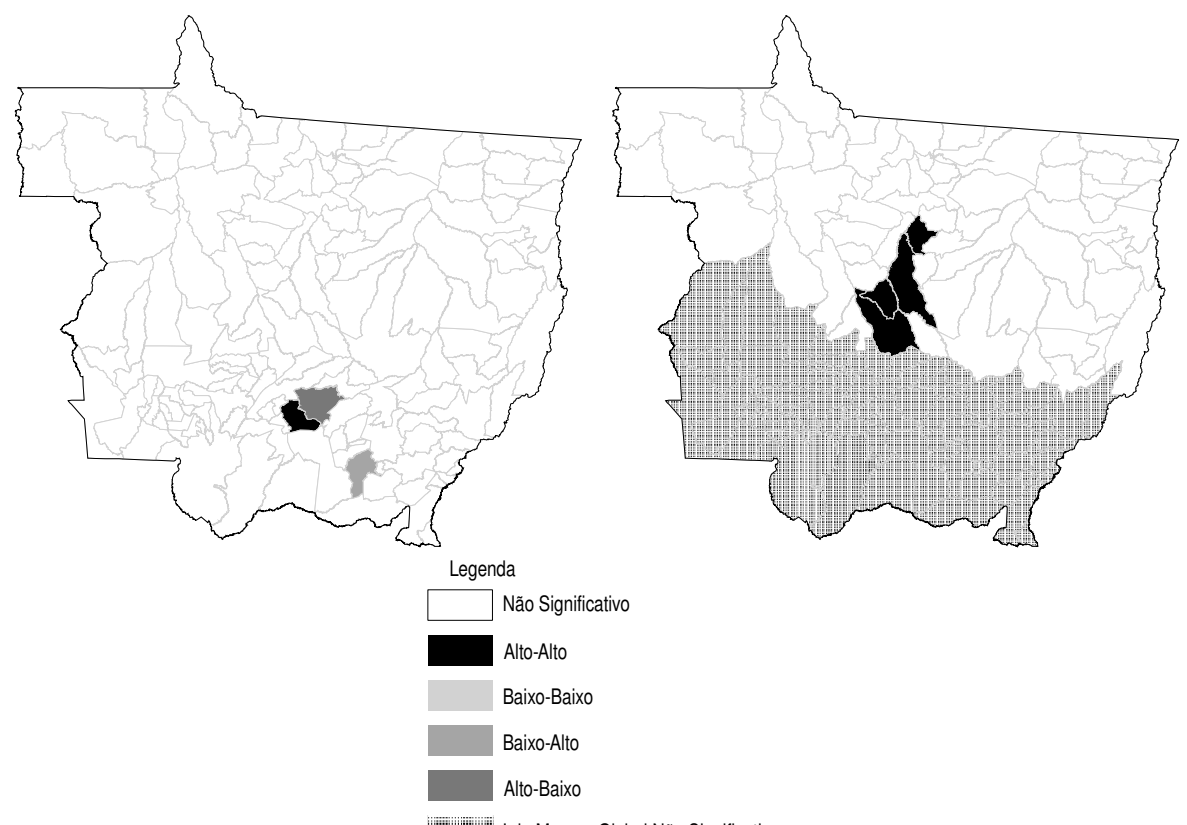

....... I de Morgan Global Não Significativo

Figura 15: Comparação do Padrão Espacial do PIB — Mato Grosso 


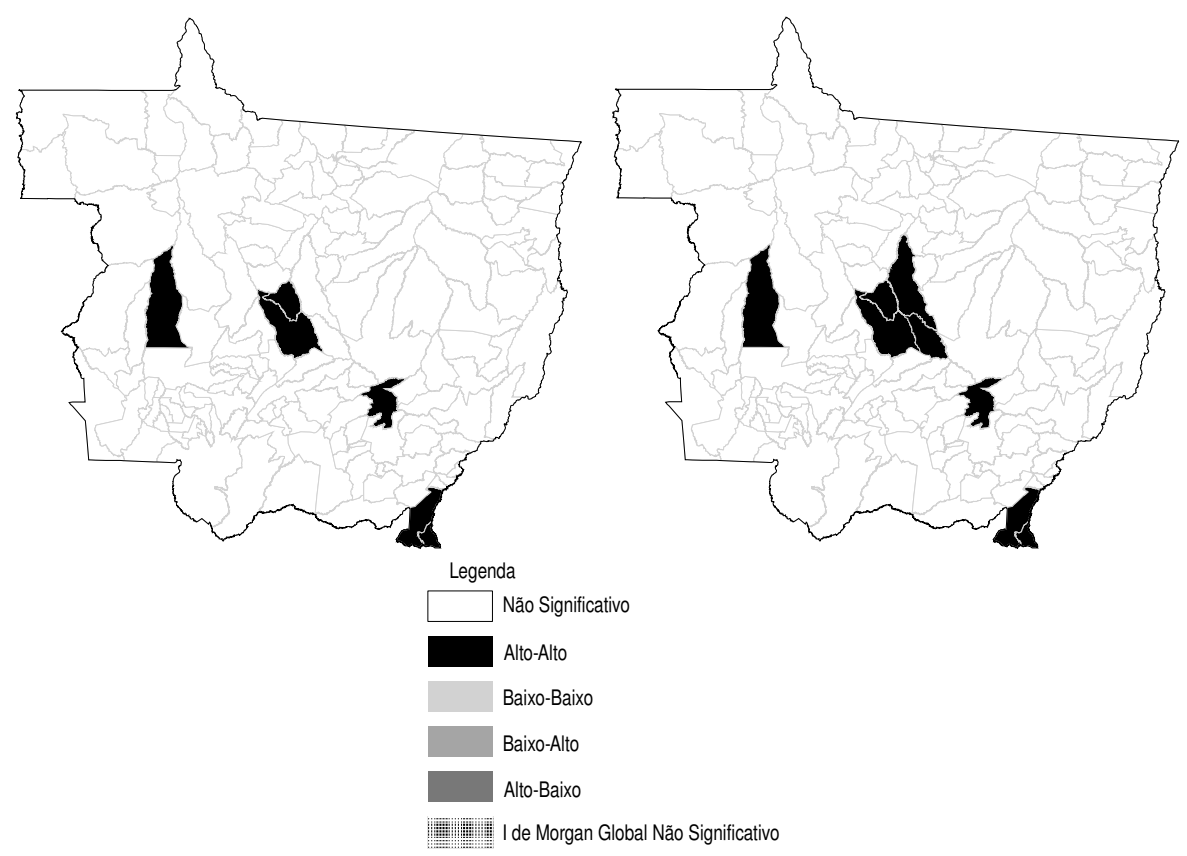

Figura 16: Comparação do Padrão Espacial do PIB per Capita - Mato Grosso

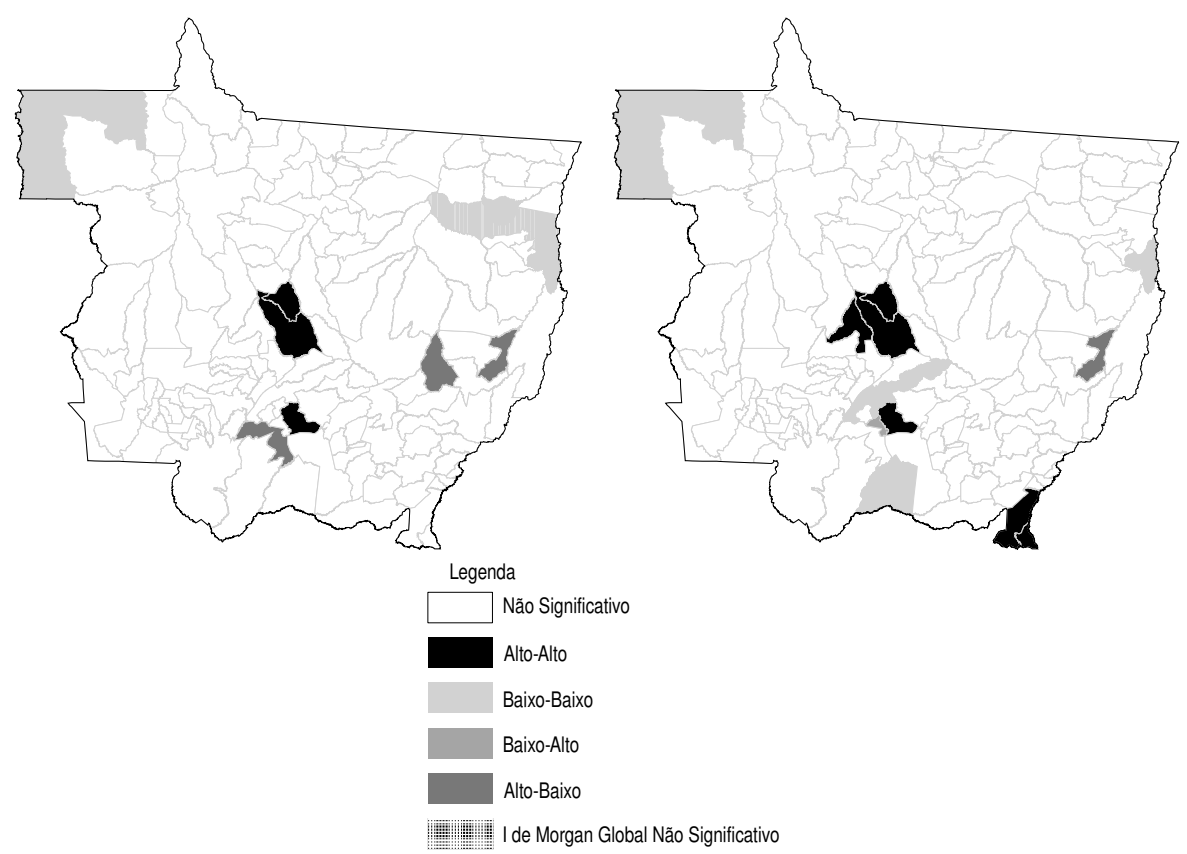

Figura 17: Comparação do Padrão Espacial do IFDM — Mato Grosso 
O método de extração considera o efeito do isolamento hipotético de uma região sobre o produto do restante da economia. Sem perda de generalidade, suponha que a primeira região seja extraída. Portanto, as $N-1$ regiões restantes representarão o restante da economia. ${ }^{7}$

Consequentemente, pode-se escrever $x=\left(x^{1^{\prime}}, x^{R^{\prime}}\right)^{\prime} \operatorname{com} x^{R}=\left(x^{2^{\prime}}, \cdots, x^{I^{\prime}}\right.$, $\left.\cdots, x^{N^{\prime}}\right)^{\prime}$ como um vetor coluna com $n(N-1)$ elementos.

De forma similar tem-se:

$$
A=\left[\begin{array}{ll}
A^{11} & A^{1 R} \\
A^{R 1} & A^{R R}
\end{array}\right]
$$

De forma análoga à equação (7), a inversa de Leontief na sua forma particionada é dada por:

$$
B=(I-A)^{-1}=\left[\begin{array}{ll}
B^{11} & B^{1 R} \\
B^{R 1} & B^{R R}
\end{array}\right]
$$

Com base na equação (8) tem-se:

$$
\begin{gathered}
x^{1}=B^{11} f^{1}+B^{1 R} f^{R} \\
x^{R}=B^{R 1} f^{1}+B^{R R} f^{R}
\end{gathered}
$$

Com a extração hipotética da região 1, o modelo na equação (3) será reduzido e assumirá a seguinte forma:

$$
\bar{x}^{R}=A^{R R} \bar{x}^{R}+f^{R}
$$

O vetor $\bar{x}^{R}$ representa o produto do restante da economia para o modelo reduzido. A solução para a equação reduzida é:

$$
\bar{x}^{R}=\left(I-A^{R R}\right)^{-1} f^{R}
$$

A diferença entre $x^{R}$ (equação $9 \mathrm{~b}$ ) e $\bar{x}^{R}$ (equação 10) fornecerá o efeito da extração da região 1 sobre o produto do restante da economia. A fim de interpretar os elementos do vetor $x^{R}-\bar{x}^{R}$, tem-se que calcular a matriz $B$ como a inversa da matriz particionada da seguinte forma:

$$
\begin{aligned}
& B^{1 R}=B^{11} A^{1 R}\left(I-A^{R R}\right)^{-1} \\
& B^{R 1}=\left(I-A^{R R}\right)^{-1} A^{R 1} B^{11} \\
& B^{R R}=\left(I-A^{R R}\right)^{-1}+\left(I-A^{R R}\right)^{-1} A^{R 1} B^{11} A^{1 R}\left(I-A^{R R}\right)^{-1}
\end{aligned}
$$

Por consequência tem-se:

$$
\begin{aligned}
x^{R}-\bar{x}^{R} & =B^{R 1} f^{1}+\left[B^{R R}-\left(I-A^{R R}\right)^{-1}\right] f^{R} \\
& =\left(I-A^{R R}\right)^{-1} A^{R 1} B^{11}\left[f^{1}+A^{1 R}\left(I-A^{R R}\right)^{-1} f^{R}\right]
\end{aligned}
$$

\footnotetext{
${ }^{7} \mathrm{O}$ sobreescrito $R$ irá representar estas regiões
} 
A interpretação da expressão $x^{R}-\bar{x}^{R}$ pode ser dividida em duas partes: a) a primeira $B^{R 1} f^{1}$ descreve a produção no restante da economia que é necessária para satisfazer a demanda final $f^{1}$ na região 1 ; e b) a segunda parte, $\left[B^{R R}-\left(I-A^{R R}\right)^{-1}\right] f^{R}$, descreve a produção no restante da economia $B^{R R} f^{R}$ que é necessária para satisfazer a demanda final no restante da economia $f^{R}$.

Pode-se observar que os elementos do vetor $x^{R}-\bar{x}^{R}$ mostram a interdependência entre a região 1 e as outras regiões. De acordo com Dietzenbacher et al. (1993), estas interdependências são fundamentalmente para trás em sua natureza. Isto pode ser mostrado utilizando a matriz $A^{R 1}$ (cujos elementos indicam a dependência para trás de $1 \mathrm{em} R$ ) e $A^{1 R}$ (cujos elementos indicam a dependência para trás de $R$ em 1 ).

Com o objetivo de melhor entender a expressão $x^{R}-\bar{x}^{R}$, utilizaremos a equação (13b) e examinaremos esta equação utilizando a ideia dos efeitos spillover inter-regional e os efeitos para trás inter-regionais desenvolvidos por Miller \& Blair (1985).

Para satisfazer a demanda final $f^{1}$ na região 1 , esta região deve produzir $B^{11} f^{1}$. A região 1 não tem todos os insumos necessários para alcançar tal nível de produto. Portanto, com o objetivo de alcançar tal nível de produção, é necessário que a região 1 adquira insumos diretamente das outras regiões. A quantidade de insumos adquirida será $A^{R 1} B^{11} f^{1}$. Para ofertar tais insumos, a produção no restante da economia deve ser $\left(I-A^{R R}\right)^{-1} A^{R 1} B^{11} f^{1}$. A mesma análise pode ser feita para o lado da demanda da economia, $f^{1}$.

Ao aplicar a ideia tradicional de feedbacks inter-regionais para a região 1 é possível afirmar que os feedbacks para esta região serão obtidos através da comparação do produto da mesma dentro do modelo inter-regional com o produto da região 1 dentro do modelo de uma região. Na forma matemática temos:

$$
x^{1}-\bar{x}^{1}=B^{11} f^{1}+B^{1 R} f^{R}-\left(I-A^{11}\right)^{-1} f^{1}
$$

Tomando as equações (12) e (13) e mudando os superescritos 1 e $R$, temos:

$$
x^{1}-\bar{x}^{1}=\left(I-A^{11}\right)^{-1} A^{1 R} B^{R R}\left[f^{R}+A^{R 1}\left(I-A^{11}\right)^{-1} f^{1}\right]
$$

Com base no método de extração regional é possível afirmar que o vetor $x^{1}-\bar{x}^{1}$ mede a dependência para trás do restante da economia em relação à região 1. Em outras palavras, o vetor permite medir qual o impacto da extração da economia das $N-1$ regiões em $R$ sobre o produto da região remanescente, 1 .

\subsection{Resultados}

As Figuras 18 a 28 apresentam a extração de cada um dos Estados a serem criados. Os resultados são apresentados nas Figuras de duas formas: à esquerda estão apresentados em percentuais do impacto total da remoção do Estado na economia, sendo que quanto mais forte a cor, maior o impacto; à direita estão apresentadas em termos de desvios-padrão, sendo consideradas faixas de um desvio-padrão em relação à média. Assim, quanto mais vermelha está a região, maiores são os impactos da extração hipotética do Estado, e quanto mais forte 
o azul, menor este impacto. As principais análises são baseadas nos gráficos à esquerda.

As atuais estruturas produtivas em cada um dos Estados envolvem complexas ligações setoriais que englobam o Estado como um todo. A separação destes Estados "quebra" essa estrutura intrarregional original, fazendo com que apenas um subconjunto de elos seja considerado dentro dos "novos" Estados, o que pode levar a uma caracterização mais específica de cada um deles, ou seja, há um direcionamento à especialização.

Uma evidência geral é a forte dependência dos Estados a serem criados em relação às regiões Sul e Sudeste, com destaque para o Estado de São Paulo. Analisando caso a caso, por sua vez, questões mais locais são possíveis de serem verificadas.

As Figuras 18 a 20 apresentam os resultados da extração hipotética de cada um dos três Estados a serem desmembrados no atual Estado do Pará. Os resultados aparecem em termos de perdas percentuais do PIB. Como destacado anteriormente, é possível perceber, a partir destes mapas, como estão conectadas a região extraída com as demais regiões no País, revelando suas principais conexões regionais.

O Estado de Tapajós apresenta ligações mais fortes com Amazonas e São Paulo, sendo que sua extração causa pouco impacto na região ao redor do Estado. O Estado do Pará, por sua vez, apresenta elos ainda mais fortes com as regiões Sul e Sudeste, porém tem uma importância maior para os demais Estados do Norte e Nordeste, principalmente o Maranhão e Maranhão do Sul e Amazonas, além dos Estados que compõem o atual território estadual do Pará. O Estado de Carajás também apresenta relações mais fortes com Sul e Sudeste, porém, diferentemente do Estado de Tapajós, seus elos são mais relevantes na região, principalmente com o Estado do Amazonas, Pará, Maranhão e Maranhão do Sul, além de Tocantins.

As ligações das estruturas produtivas maranhense (Figura 21) e sul-maranhense (Figura 22) mostram-se mais diferentes, sendo que remoção da primeira tem forte impacto no Piauí, Ceará, Pará e Amazonas, além de algum impacto em Carajás e Tapajós, enquanto a remoção do estado do Maranhão do Sul causaria maiores impactos no Pará, Carajás, Tocantins e Maranhão. Destaca-se novamente que os maiores impactos estão concentrados nas regiões Sul e Sudeste, evidenciando o forte caráter desigual da estrutura produtiva nacional, que é fortemente concentradora.

Dos Estados analisados, o Estado do Piauí (Figura 23) é um dos que apresenta impactos territorialmente mais abrangentes quando extraído. Além dos impactos no Sul e Sudeste, a extração deste Estado causa perdas em todo o Nordeste com destaque para Bahia, Ceará, Maranhão e Pernambuco, além de haver ligações relevantes com o Centro-Oeste, com destaque para Goiás, e com o Amazonas. O Estado de Gurgueia (Figura 24), em contraste, apresenta ligações mais fortes com Estados ao seu redor, principalmente na região Nordeste, com destaque para Bahia e Ceará, evidenciando um caráter mais regional desta economia.

Ao extrair hipoteticamente o Estado da Bahia (Figura 25) e do Rio São Francisco (Figura 26) os resultados são muito semelhantes, sendo que além da dependência do Sul e Sudeste há impactos no Nordeste principalmente em Sergipe, Pernambuco e Ceará. As diferenças são a maior dependência de Rio São Francisco em relação à Bahia e da Bahia em relação ao Amazonas, o que não ocorre com Rio São Francisco, refletindo uma economia mais local deste 

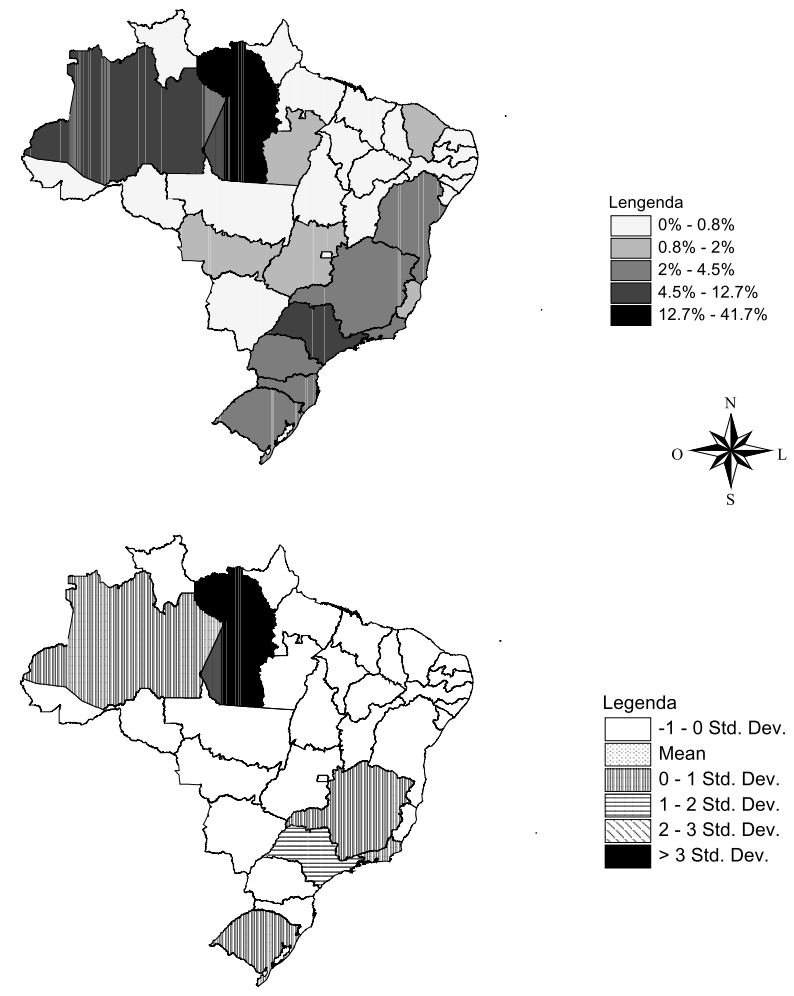

Figura 18: Resultados da Extração de Tapajós
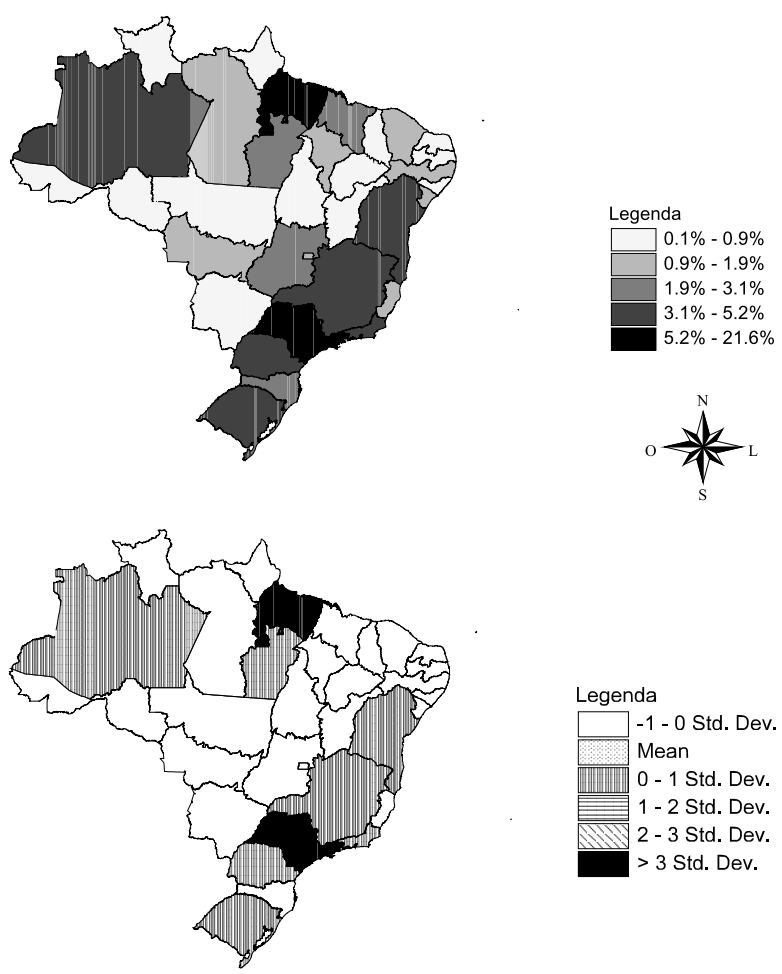

Figura 19: Resultados da Extração do Pará 

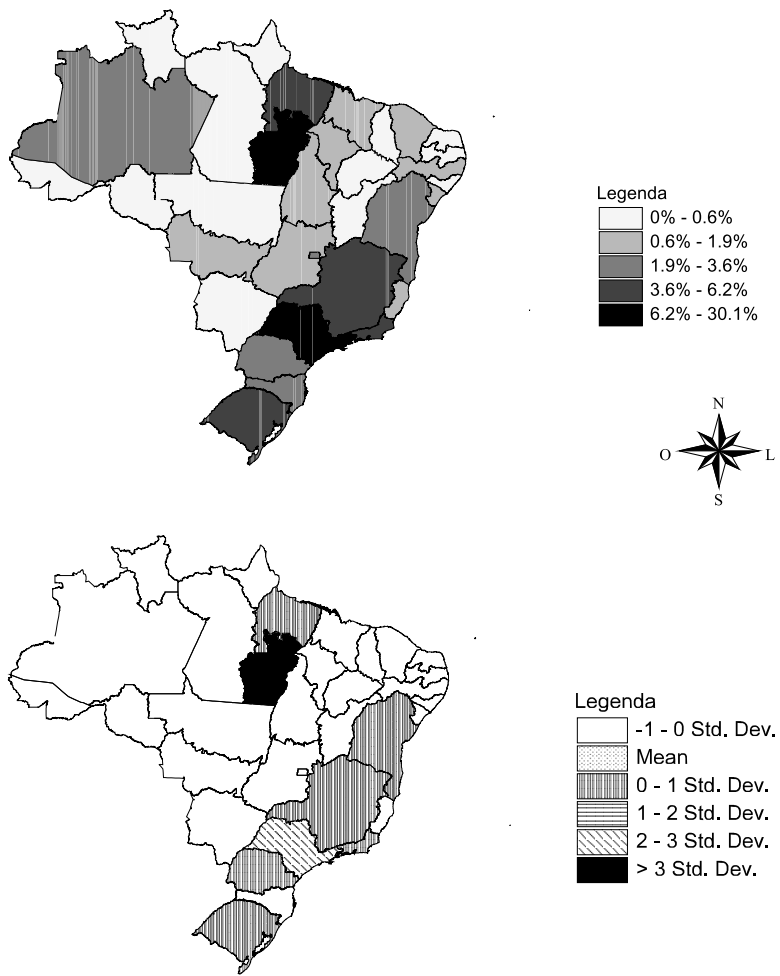

Figura 20: Resultados da Extração de Carajás
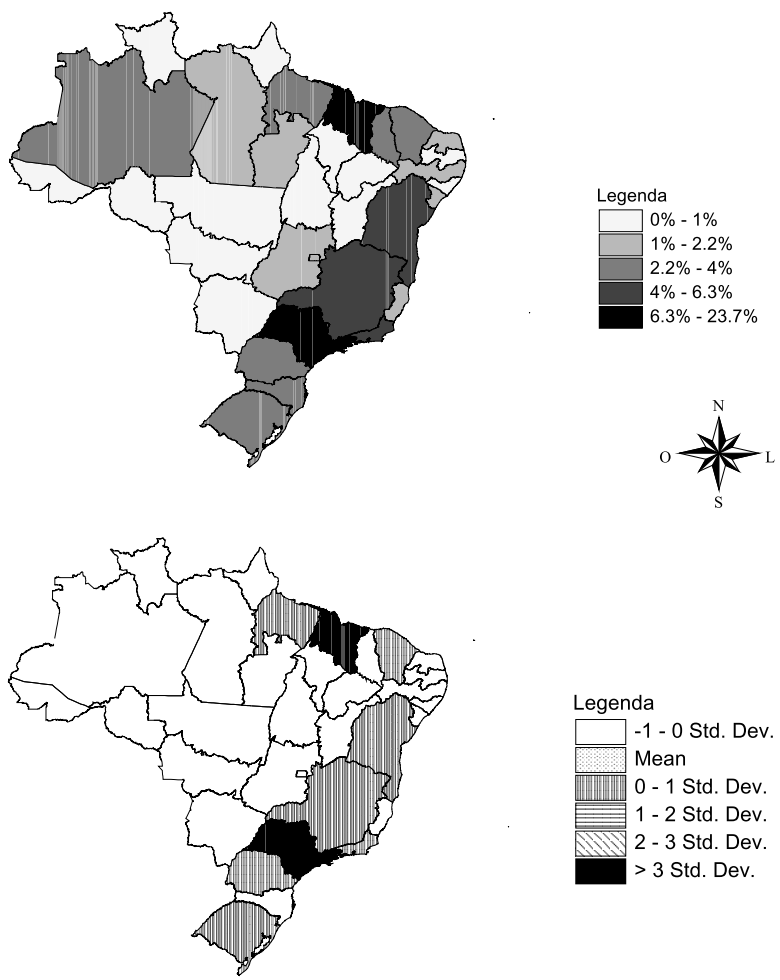

Figura 21: RResultados da Extração do Maranhão 

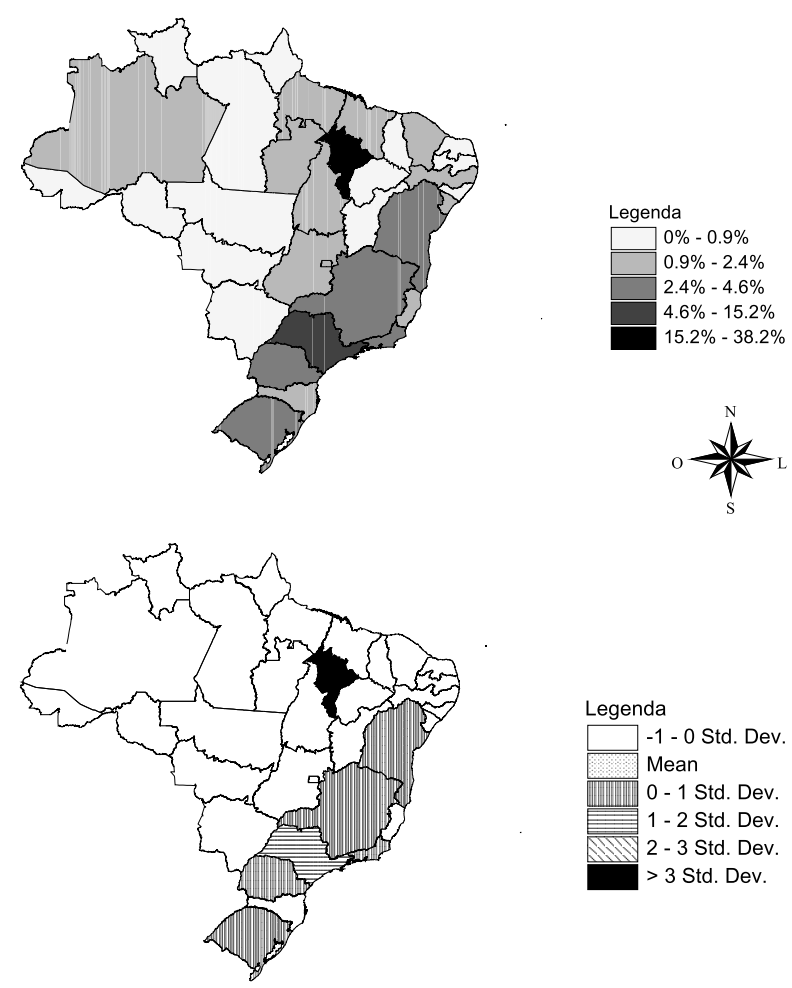

Figura 22: Resultados da Extração do Maranhão do Sul

em relação àquele. Em outras palavras, o encadeamento produtivo do Estado do Rio São Francisco é relativamente mais concentrado espacialmente.

Por fim, extraindo-se os Estados do Mato Grosso e Mato Grosso do Norte, Figuras 27 e 28, respectivamente, destaca-se a maior dependência desses Estados em relação à região Centro-Oeste, principalmente Goiás, e ao Estado do Amazonas. Nota-se ainda que há maior ligação de dependência do Estado do Mato Grosso do Norte em relação ao Estado do Mato Grosso, do que o inverso.

\section{Nova Configuração das Transferências Governamentais}

O Fundo de Participação dos Estados e o Fundo de Participação dos Municípios, FPE e FPM, respectivamente, foram criados na Lei 5.172 de 1966 tendo, entretanto, passado por modificações com o tempo. Destas modificações, a Resolução n. 242 de 1990 do TCU (Tribunal de Contas da União) apresenta os coeficientes estaduais do FPE e FPM interior que passaram a vigorar a partir de 1991, e define os demais coeficientes a serem aplicados na metodologia de cálculo, sendo que não houve modificações desde então.

De acordo com a Emenda Constitucional n. 55 de 2007, o FPE é constituído por $21,5 \%$ do total arrecadado com IPI (Imposto sobre Produto Industrializado) e $21,5 \%$ do IR (Imposto de Renda). O FPM, por sua vez, é constituído por $22,5 \%$ de cada um dos tributos mencionados com um adicional de $1 \%$ que é pago somente no mês de dezembro. Neste exercício de simulação das transferências não será utilizado este percentual adicional. 

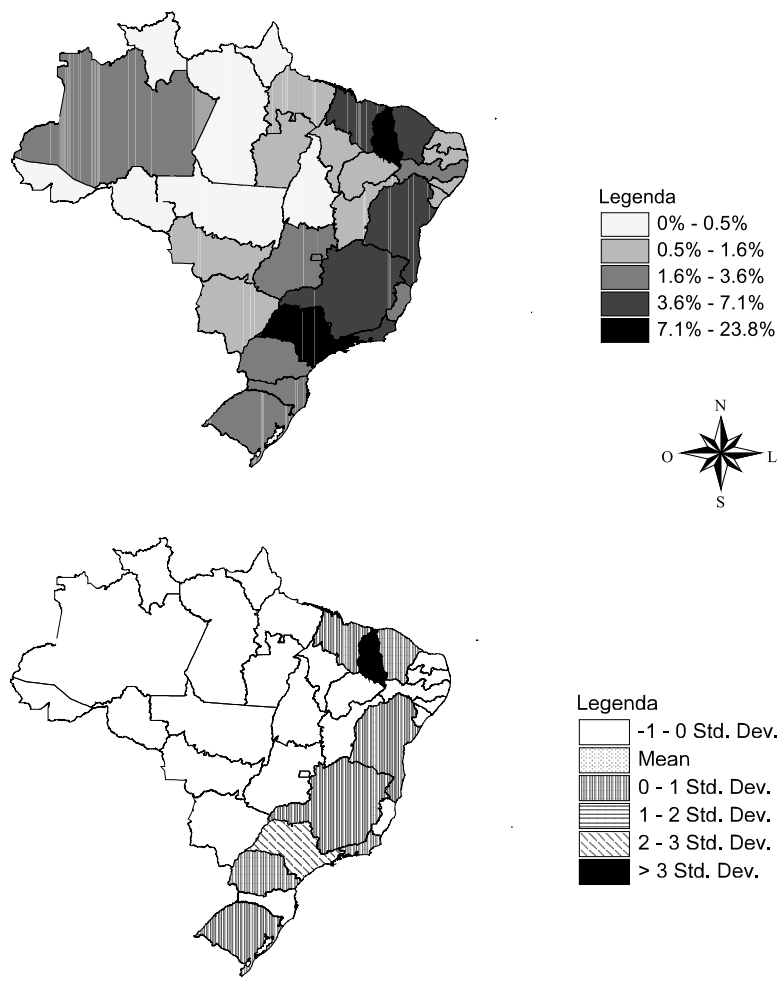

Figura 23: Resultados da Extração de Piauí
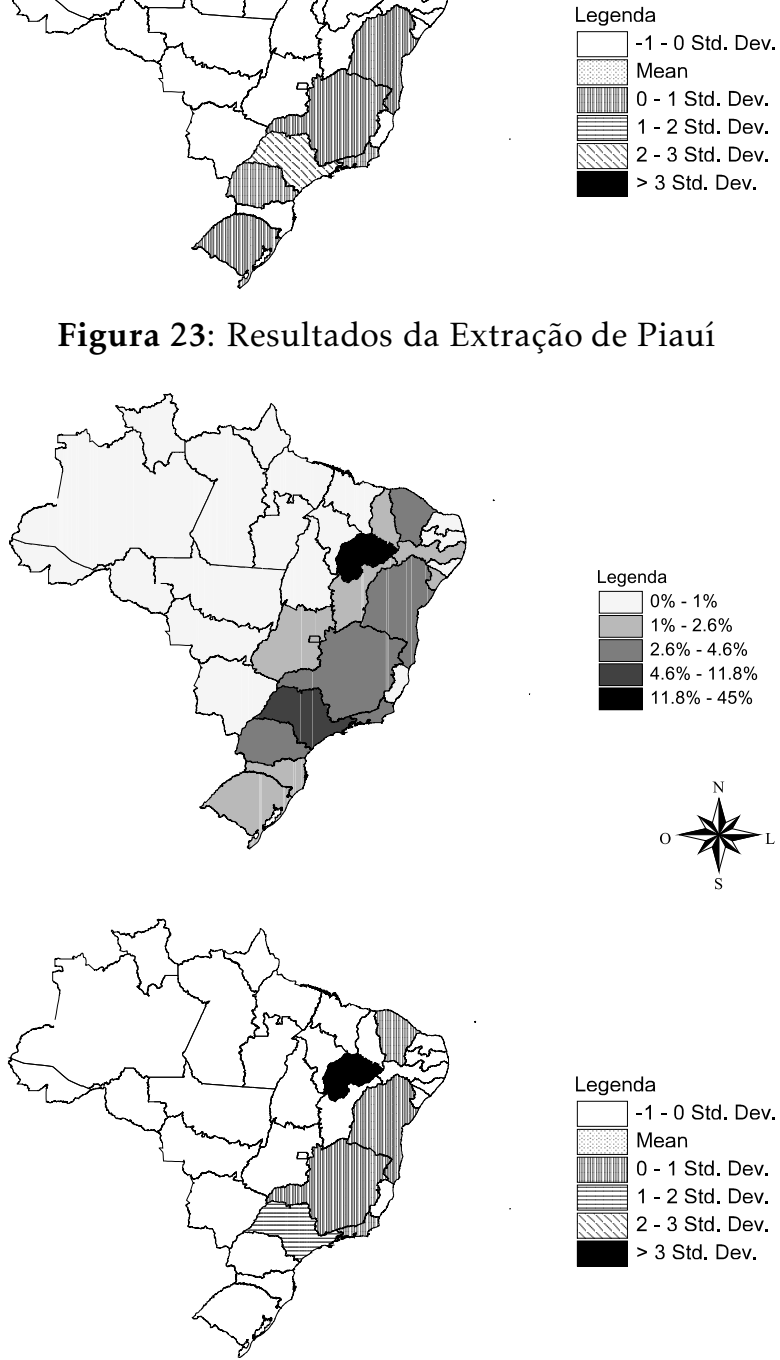

Figura 24: Resultados da Extração de Gurgueia 

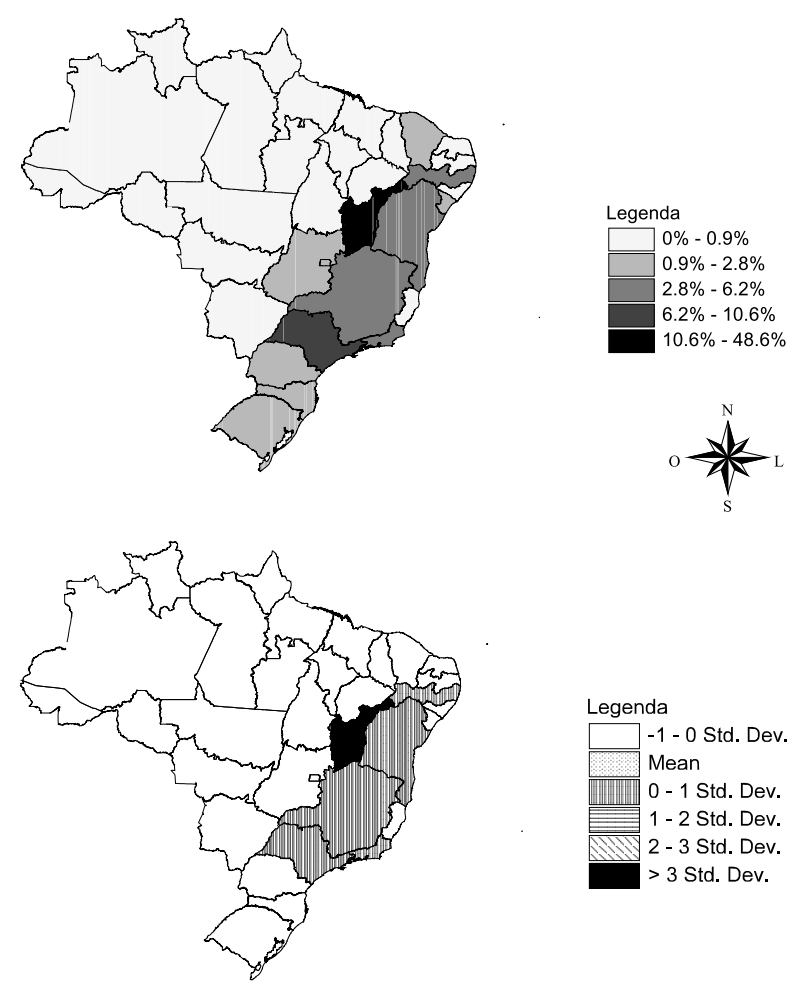

Figura 25: Resultados da Extração da Bahia

A metodologia de cálculo de FPE apresentada pela Lei 5.172 de 1966 definia que o coeficiente seria composto por: $5 \%$ proporcionalmente à superfície do Estado e $95 \%$ proporcionalmente ao coeficiente obtido pela multiplicação do fator da população e do fator do inverso da renda per capita. Com a modificação realizada em 1990, os Estados do Sul e Sudeste passaram a receber $15 \%$ do FPE e os demais 85\% do Fundo. Assim tem-se:

$$
c F P E=0,05 f \text { Area }+0,95(f \text { Pope } * f \text { Rend } a)
$$

onde:

cFPE é o coeficiente de FPE;

$f$ Area é o fator referente à área;

fPope é o fator referente à população estadual;

$f$ Renda é o fator referente à renda.

O fator fArea é a proporção da superfície do Estado em relação à superfície do País. O fator $f$ Pope é um fator definido a partir da proporção da população da unidade da Federação na população nacional, enquanto o fator $f$ Renda é um fator definido a partir do inverso da renda per capita estadual. As tabelas de fatores para o cálculo do FPE são apresentadas na Lei 5127/1967. Como mencionado, $85 \%$ do FPE são destinados para as macrorregiões Norte, Nordeste e Centro-Oeste.

Para definição dos novos coeficientes pós-separação, assumiu-se que a estrutura de participação macrorregional permanecesse constante. Ainda, o cál- 

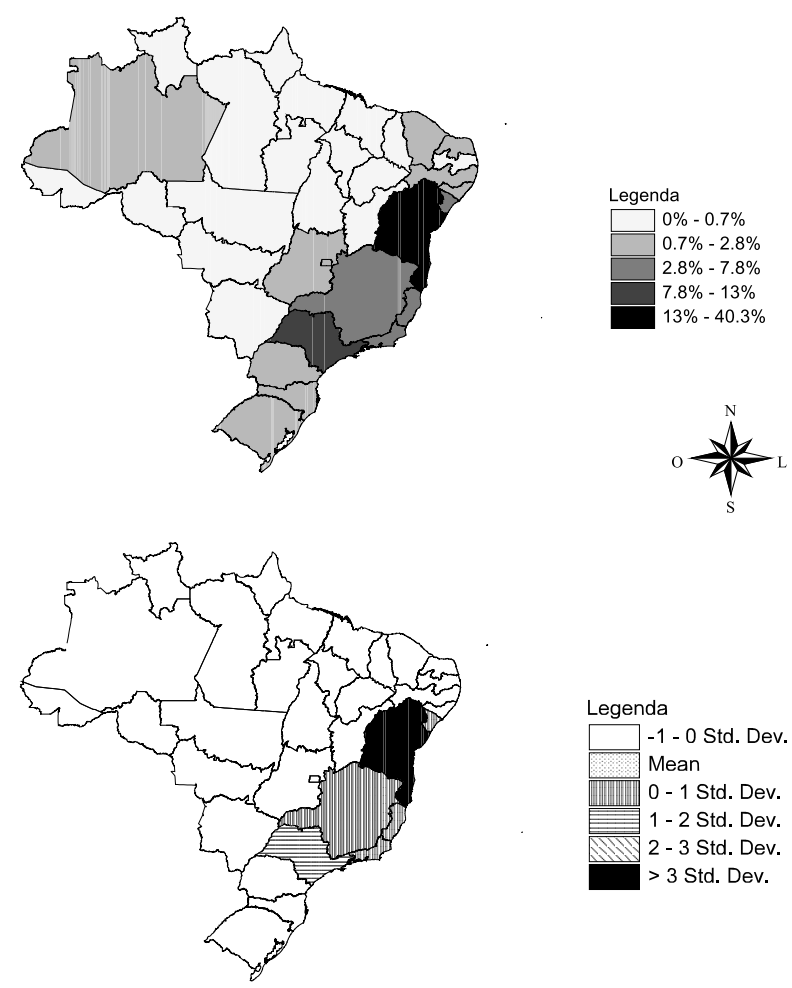

Figura 26: Resultados da Extração de Rio São Francisco

culo do FPE foi refeito, tomando como base os dados atuais de forma que se pudessem comparar os resultados da simulação.

A distribuição do FPM para os municípios foi realizada como segue: (i) as capitais recebem $10 \%$ do Fundo; (ii) os municípios de reserva ${ }^{8}$ recebem 3,6\% do Fundo; e (iii) todos os municípios do interior, inclusive os de reserva, recebem $86,4 \%$ do Fundo. Os coeficientes do FPM-Capitais são obtidos pela proporção do fator obtido pela multiplicação do fator de população municipal e inverso da renda per capita estadual. Para o FPM-Interior o coeficiente é obtido pela proporção, no Estado, do fator população. Para o FPM-Reserva o coeficiente é obtido pela proporção do fator resultante da multiplicação do fator população com o fator inverso da renda per capita estadual. As tabelas de fatores utilizadas para o FPM podem ser obtidas no TC $026.778 / 2007-3$ do TCU. Logo:

$$
\begin{aligned}
& c F P M c_{j}=c F P M c_{i}=\frac{f P o p m_{i} j * f \operatorname{Rend}_{i}}{\sum_{i} f \operatorname{Popm}_{i j} * f \operatorname{Rend} a_{j}} \\
& c F P M r_{j}=\sum_{i} c F P M r_{i}=\sum_{i} \frac{f \text { Popm }_{i j} * f \text { Rend }_{j}}{\sum_{i} f \text { Popm }_{i j} * f \text { Rend }_{j}} \\
& c F P M i_{j}=\frac{\sum_{j} \text { fPopm }_{i j}}{\sum_{i} \text { f Popm }_{i}}
\end{aligned}
$$

\footnotetext{
${ }^{8}$ Aqueles com mais de 142.633 habitantes
} 

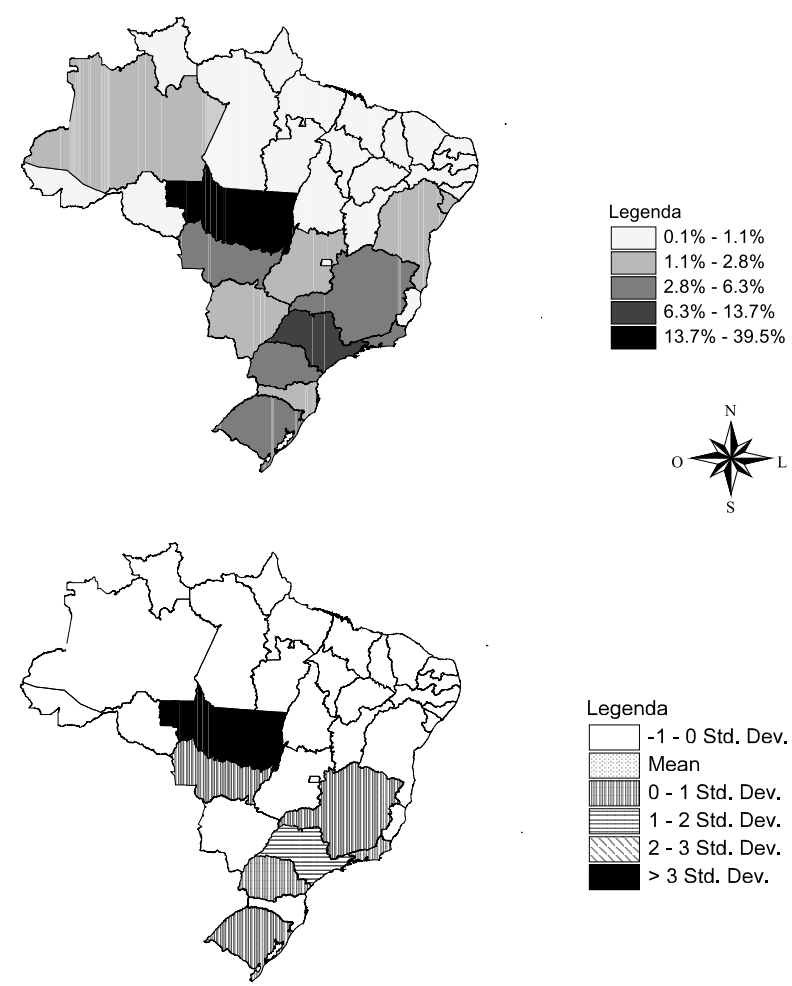

Figura 27: Resultados da Extração do Mato Grosso

$$
c F P M_{j}=0,10 * c F P M c_{j}+0,036 * c F P M i_{j}+0,864 * c F P M r_{j}
$$

onde:

o subscrito $i$ se refere ao município e o subscrito $j$ se refere ao Estado;

$c F P M c_{k}$ é o coeficiente de FPM-Capitais, tal que $k=i, j$;

$c F P M r_{k}$ é o coeficiente de FPM-Reserva, tal que $k=i, j$;

$c F P M i_{k}$ é o coeficiente de FPM-Interior, tal que $k=i, j$;

$c F P M_{j}$ é o coeficiente estadual de FPM;

$f P o p m_{i j}$ é o fator relativo à população municipal;

$f R e n d a_{j}$ é o fator relativo ao inverso da renda per capita estadual.

Neste exercício de simulação das transferências governamentais com a nova configuração das Unidades da Federação, foram utilizadas estimativas de PIB per capita como proxy para renda per capita. Para o cálculo do FPMReserva, uma nova tabela de distribuição estadual foi elaborada de acordo com a atual, ou seja, a partir da proporção da soma do fator de população. A Tabela 3 apresenta os valores monetários estimados transferidos para cada UF. Para fins de comparação, foram utilizados os coeficientes calculados da mesma forma com e sem as divisões propostas.

A análise da Tabela 3 evidencia que os Estados desmembrados passariam a receber um maior valor de transferências governamentais, sendo que os Estados da própria região seriam os que mais perderiam para que houvesse tal repasse para as novas unidades federativas. O único caso em que isso não ocorre é para o desmembramento do Mato Grosso, em que haveria perda de 

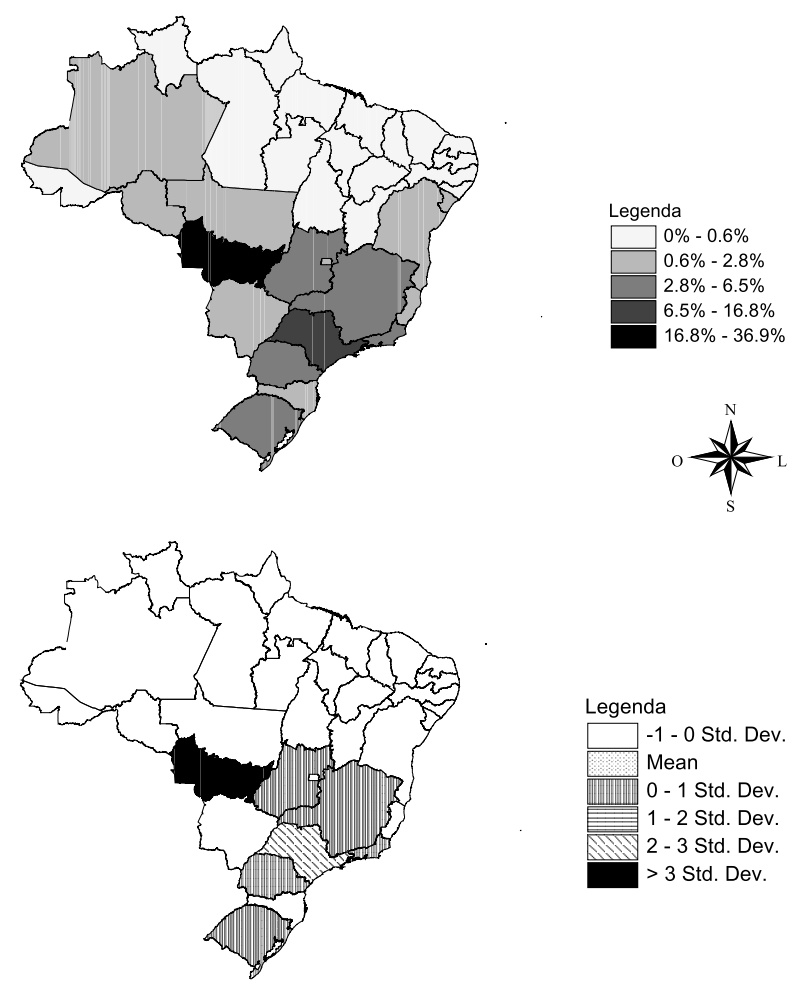

Figura 28: Resultados da Extração do Mato Grosso do Norte

transferências se somado o que seria repassado para ambos os Estados desmembrados em comparação com o Estado único. Nota-se que pela simulação, toda a região Centro-Oeste estaria perdendo repasses.

Todavia, a análise da nova estrutura de transferências não evidencia apenas os impactos diretos do novo contexto federativo, visto que há também efeitos indiretos associados às cadeias produtivas acionadas pelos gastos do governo decorrentes dos fundos constitucionais. Assim, na mesma linha de Haddad et al. (2011), foram realizadas simulações de choques de demanda final em uma estrutura de insumo-produto inter-regional estimada para as 33 UF brasileiras, considerando até 110 produtos e 56 setores em cada uma das regiões do sistema.

A Tabela 4 apresenta o vetor de choques e impactos totais gerados pelos gastos do governo no produto total de cada Estado. O vetor de choques foi construído a partir da distribuição estadual dos valores estimados das transferências. ${ }^{9}$ Além disso, por não haver informações disponíveis para a distribuição atual das transferências dentro dos Estados a serem desmembrados, as simulações contrafactuais foram feitas assumindo-se três diferentes estruturas para a distribuição intraestadual das transferências atuais. Consideraram-se distribuições hipotéticas tomando-se como base as participações das regiões correspondentes aos territórios dos novos Estados dentro do Estado de origem. Três variáveis foram utilizadas como referência: (i) PIB da Administração Pú-

\footnotetext{
${ }^{9}$ Obteve-se uma correlação de $93,8 \%$ entre os valores estimados e os valores observados em 2008, o que garante uma boa aproximação da estrutura vigente de transferências.
} 
Tabela 3: Transferências Governamentais Estimadas, em Milhões de Reais

\begin{tabular}{|c|c|c|c|c|c|c|}
\hline \multirow{2}{*}{ Estados Atuais } & \multirow{2}{*}{$\begin{array}{l}\text { Estados } \\
\text { Desmembrados }\end{array}$} & \multicolumn{2}{|c|}{ FPE } & \multicolumn{2}{|c|}{ FPM } & \multirow{2}{*}{ Diferença } \\
\hline & & Antes & Depois & Antes & Depois & \\
\hline Rondônia & & 1.174 & 1.029 & 413 & 477 & -81 \\
\hline Acre & & 1.327 & 1.162 & 232 & 263 & -134 \\
\hline Amazonas & & 1.454 & 1.204 & 599 & 634 & -215 \\
\hline Roraima & & 1.170 & 1.025 & 141 & 155 & -132 \\
\hline \multirow[t]{4}{*}{ Pará } & & 3.872 & - & 1.770 & - & \\
\hline & Tapajós & - & 2.212 & - & 475 & \multirow{3}{*}{1.479} \\
\hline & Pará & - & 1.955 & - & 1.157 & \\
\hline & Carajás & - & 882 & - & 441 & \\
\hline Amapá & & 1.142 & 999 & 164 & 196 & -110 \\
\hline Tocantins & & 1.370 & 1.041 & 656 & 769 & -216 \\
\hline \multirow[t]{3}{*}{ Maranhão } & & 3.535 & - & 2.066 & - & \\
\hline & Maranhão & - & 2.781 & - & 1.743 & \multirow[t]{2}{*}{836} \\
\hline & Maranhão do Sul & - & 1.388 & - & 526 & \\
\hline \multirow[t]{3}{*}{ Piauí } & & 2.039 & - & 1.221 & - & \multirow{3}{*}{811} \\
\hline & Piauí & - & 556 & - & 986 & \\
\hline & Gurguéia & - & 1.909 & - & 620 & \\
\hline Ceará & & 3.736 & 3.204 & 2.380 & 2.179 & -733 \\
\hline Rio Grande do Norte & & 1.272 & 1.211 & 1.157 & 1.105 & -114 \\
\hline Paraíba & & 1.588 & 1.511 & 1.499 & 1.448 & -127 \\
\hline Pernambuco & & 3.352 & 2.838 & 2.515 & 2.248 & -781 \\
\hline Alagoas & & 1.972 & 1.503 & 1.092 & 965 & -597 \\
\hline Sergipe & & 1.106 & 1.052 & 679 & 660 & -72 \\
\hline \multirow[t]{3}{*}{ Bahia } & & 5.196 & - & 4.334 & - & \\
\hline & Rio São Francisco & - & 1.246 & - & 432 & \multirow[t]{2}{*}{487} \\
\hline & Bahia & - & 4.597 & - & 3.741 & \\
\hline Minas Gerais & & 1.732 & 1.707 & 6.233 & 5.985 & -274 \\
\hline Espírito Santo & & 238 & 261 & 799 & 750 & -27 \\
\hline Rio de Janeiro & & 851 & 938 & 1.413 & 1.459 & 131 \\
\hline São Paulo & & 1.026 & 943 & 6.381 & 6.103 & -362 \\
\hline Paraná & & 1.254 & 1.254 & 3.254 & 2.974 & -280 \\
\hline Santa Catarina & & 585 & 586 & 1.892 & 2.038 & 147 \\
\hline Rio Grande do Sul & & 1.118 & 1.116 & 3.256 & 3.425 & 167 \\
\hline Mato Grosso do Sul & & 838 & 672 & 692 & 647 & -211 \\
\hline \multirow[t]{3}{*}{ Mato Grosso } & & 844 & - & 875 & - & \multirow{3}{*}{527} \\
\hline & Mato Grosso do & - & 661 & - & 495 & \\
\hline & Mato Grosso & - & 540 & - & 550 & \\
\hline Goiás & & 1.276 & 1.121 & 1.725 & 1.750 & -129 \\
\hline Distrito Federal & & 297 & 260 & 35 & 80 & 8 \\
\hline Brasil & & 45.364 & 45.364 & 47.474 & 47.474 & 0 \\
\hline
\end{tabular}


Tabela 4: Transferências Governamentais Estimadas, em Milhões de Reais

\begin{tabular}{|c|c|c|c|c|c|c|c|c|}
\hline \multirow{2}{*}{ UF } & \multicolumn{4}{|c|}{ Choque dos Gastos do Governo } & \multicolumn{4}{|c|}{ Impacto dos Gastos do Governo } \\
\hline & Divisão & $\mathrm{APU}^{*}$ & PIB & POP & Divisão & $\mathrm{APU}^{*}$ & PIB & POP \\
\hline $\mathrm{RO}$ & 1.506 & 1.587 & 1.587 & 1.587 & 1.784 & 1.873 & 1.872 & 1.873 \\
\hline $\mathrm{AC}$ & 1.425 & 1.559 & 1.559 & 1.559 & 1.605 & 1.753 & 1.753 & 1.753 \\
\hline $\mathrm{AM}$ & 1.838 & 2.054 & 2.054 & 2.054 & 2.616 & 2.800 & 2.792 & 2.799 \\
\hline RR & 1.180 & 1.311 & 1.311 & 1.311 & 1.356 & 1.499 & 1.498 & 1.499 \\
\hline TA & 2.687 & 821 & 607 & 874 & 2.953 & 933 & 701 & 991 \\
\hline PA & 3.113 & 3.845 & 3.426 & 3.777 & 3.845 & 4.667 & 4.194 & 4.583 \\
\hline CA & 1.323 & 977 & 1.610 & 992 & 1.508 & 1.131 & 1.812 & 1.148 \\
\hline $\mathrm{AP}$ & 1.195 & 1.305 & 1.305 & 1.305 & 1.325 & 1.441 & 1.441 & 1.441 \\
\hline TO & 1.810 & 2.026 & 2.026 & 2.026 & 2.095 & 2.323 & 2.327 & 2.326 \\
\hline MA & 4.523 & 4.706 & 4.297 & 4.518 & 5.294 & 5.503 & 5.042 & 5.268 \\
\hline MAS & 1.913 & 895 & 1.304 & 1.083 & 2.198 & 1.058 & 1.516 & 1.268 \\
\hline PI & 1.541 & 2.535 & 2.623 & 713 & 1.947 & 3.059 & 3.153 & 1.002 \\
\hline GU & 2.529 & 724 & 636 & 2.547 & 2.797 & 821 & 725 & 2.813 \\
\hline $\mathrm{CE}$ & 5.383 & 6.116 & 6.116 & 6.116 & 7.171 & 8.049 & 8.047 & 8.052 \\
\hline $\mathrm{RN}$ & 2.316 & 2.430 & 2.430 & 2.430 & 3.044 & 3.188 & 3.188 & 3.191 \\
\hline PB & 2.959 & 3.086 & 3.086 & 3.086 & 3.547 & 3.705 & 3.705 & 3.707 \\
\hline $\mathrm{PE}$ & 5.086 & 5.867 & 5.867 & 5.867 & 7.386 & 8.378 & 8.377 & 8.379 \\
\hline $\mathrm{AL}$ & 2.467 & 3.064 & 3.064 & 3.064 & 3.010 & 3.693 & 3.693 & 3.693 \\
\hline SE & 1.713 & 1.785 & 1.785 & 1.785 & 2.155 & 2.246 & 2.246 & 2.246 \\
\hline $\mathrm{RF}$ & 1.678 & 607 & 602 & 596 & 1.957 & 751 & 746 & 739 \\
\hline BA & 8.338 & 8.922 & 8.927 & 8.934 & 11.306 & 12.021 & 12.024 & 12.036 \\
\hline MG & 7.691 & 7.966 & 7.966 & 7.966 & 11.065 & 11.347 & 11.355 & 11.357 \\
\hline ES & 1.011 & 1.037 & 1.037 & 1.037 & 1.525 & 1.555 & 1.555 & 1.555 \\
\hline RJ & 2.396 & 2.265 & 2.265 & 2.265 & 5.391 & 5.187 & 5.182 & 5.209 \\
\hline SP & 7.045 & 7.407 & 7.407 & 7.407 & 17.586 & 17.788 & 17.808 & 17.869 \\
\hline PR & 4.228 & 4.508 & 4.508 & 4.508 & 6.486 & 6.811 & 6.812 & 6.815 \\
\hline SC & 2.624 & 2.478 & 2.478 & 2.478 & 4.071 & 3.876 & 3.876 & 3.876 \\
\hline RS & 4.541 & 4.374 & 4.374 & 4.374 & 7.088 & 6.828 & 6.829 & 6.832 \\
\hline MS & 1.319 & 1.530 & 1.530 & 1.530 & 1.740 & 1.987 & 1.988 & 1.987 \\
\hline $\mathrm{MN}$ & 1.155 & 589 & 578 & 590 & 1.379 & 733 & 721 & 734 \\
\hline MT & 1.090 & 1.129 & 1.140 & 1.128 & 1.448 & 1.481 & 1.494 & 1.480 \\
\hline GO & 2.871 & 3.000 & 3.000 & 3.000 & 4.145 & 4.272 & 4.276 & 4.274 \\
\hline DF & 340 & 332 & 332 & 332 & 1.454 & 1.388 & 1.398 & 1.396 \\
\hline BRASIL & 92.838 & 92.838 & 92.838 & 92.838 & 134.278 & 134.145 & 134.145 & 134.192 \\
\hline
\end{tabular}

Fonte: Resultado da Pesquisa.

Nota:* PIB da Administração Pública.

blica; (ii) PIB; e (iii) população.

Com a nova configuração territorial, os novos Estados criados, com exceção daqueles que manteriam as capitais atuais dentro de seus limites, apresentariam, sistematicamente ganhos diretos - maior participação nos fundos constitucionais. Estes novos Estados apresentariam também aumento na participação dos impactos dos fundos constitucionais. Contudo, dada a dependência estrutural elevada em diferentes níveis hierárquicos, seja em relação à região central do Estado de origem ou em relação ao núcleo duro da economia brasileira, esses efeitos seriam reduzidos por vazamentos inter-regionais.

As regiões centrais dos Estados desmembrados, por sua vez, tenderiam a perder participação tanto dos fundos quanto nos impactos. Entretanto, o diferencial negativo associado aos impactos totais tenderia a ser arrefecido pelos efeitos intersetoriais e inter-regionais. A análise de extração hipotética, na seção anterior, evidenciou uma forte dependência produtiva arraigada nos Estados desmembrados. No caso da AEDE, na seção 3, emergiram regimes espaciais que caracterizam estruturas de dependência espacial, dentro dos atuais 
Estados, polarizadas pelas regiões das capitais.

Analisando os resultados das Tabelas 4 e 5, à luz dos resultados da seção 4, é possível afirmar que, em um nível hierárquico mais elevado, percebe-se uma dependência dos Estados desmembrados - aqueles que foram criados a partir dos já existentes - a polos macrorregionais e nacionais. Em uma análise mais local, os seguintes padrões são verificados: Tapajós possui dependência macrorregional do Amazonas; Carajás do Pará; Maranhão do Sul da Bahia; Gurgueia do Ceará; Rio São Francisco da Bahia e Pernambuco; e Mato Grosso do Norte do Mato Grosso.

Nos casos em que a dependência macrorregional estaria mais diretamente associada aos territórios dos novos Estados que mantivessem as capitais de origem (Pará, Bahia e Mato Grosso), pode-se afirmar com maior segurança que os processos separatistas tenderiam a beneficiar as regiões periféricas destes Estados, com perdas para as regiões centrais, configurando um processo de redistribuição espacial da atividade. Entretanto, as diferenças entre as participações dos "novos" Estados nos efeitos diretos (estrutura de transferências constitucionais) seriam superiores às diferenças entre as respectivas participações nos impactos totais, uma vez que as regiões centrais possuem um papel polarizador relevante. Para os outros Estados (Piauí e Maranhão), não se pode afirmar com a mesma segurança que tal padrão tenderia a se verificar, uma vez que há incertezas sobre o atual processo de distribuição intraestadual das transferências e, de acordo com nossas simulações, os resultados são sensíveis aos três conjuntos de hipóteses assumidas nos exercícios contrafactuais.

Em relação aos demais Estados da Federação, uma análise da nova estrutura de transferências sugere que, com poucas exceções, haveria perdas diretas em favor dos territórios dos Estados originais desmembrados. Contudo, dada a estrutura de dependência, analisada na seção anterior, os impactos totais da nova configuração dos gastos governamentais vinculados às transferências reduziriam as perdas diretas de muitos Estados que se beneficiariam de vazamentos produtivos. Esse resultado pode ser percebido pelas diferenças das magnitudes das perdas de participação relativas aos choques (estrutura de transferência) e aos impactos. Em outras palavras, as diferenças de participação nos choques tendem a ser maiores que as diferenças de participação nos impactos totais.

\section{Considerações Finais}

Existem três questões na literatura de separatismo que podem ser discutidos à luz de nossos resultados. As três questões são: a) a dicotomia entre motivos econômicos e políticos no processo de separação; b) a relação entre integração/interdependência econômica e custos do processo de separação e; c) a correlação entre tamanho da região e renda per capita.

Em relação ao primeiro ponto, Hansen (1978) afirma ser difícil explicar o processo de separatismo em termos das diferenças regionais e, portanto, tratar a questão sob a forma econômica. O autor afirma que há processos de separação tanto em regiões com nível de renda abaixo da média como em regiões com nível de renda acima da média. Para o caso brasileiro, podemos afirmar que os resultados da análise exploratória de dados espaciais e a análise das transferências presentes neste trabalho possibilitaram trazer argumentos de 


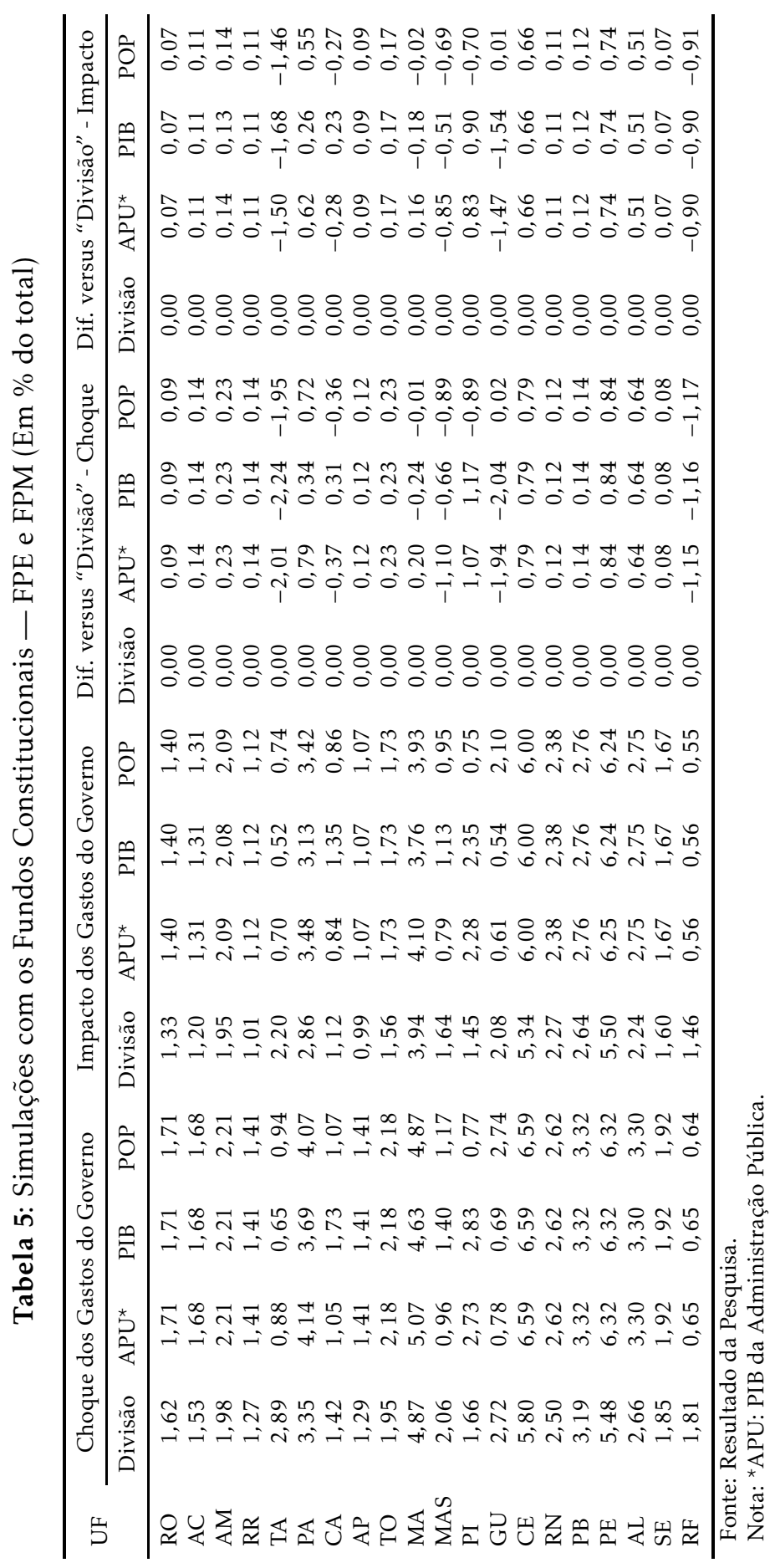




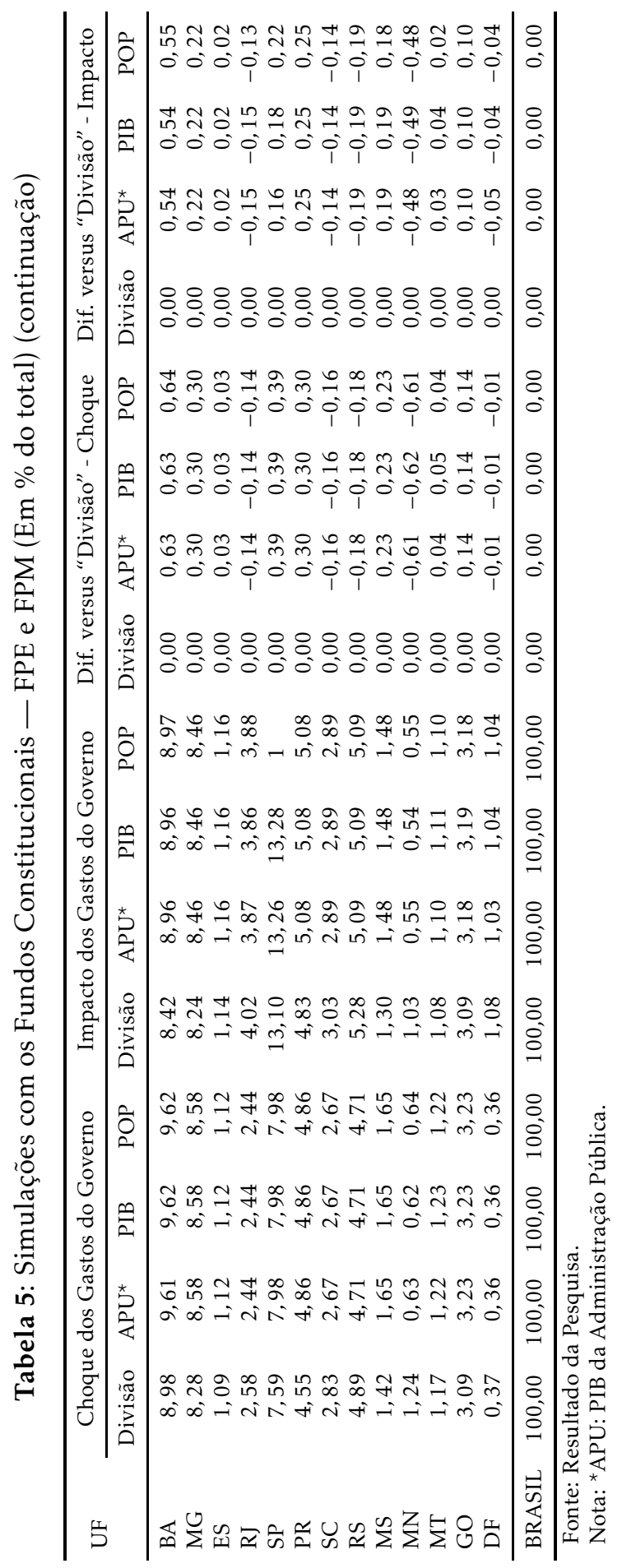


cunho econômico para o debate sobre o processo de fragmentação da economia brasileira.

No que tange à relação entre o grau de integração/interdependência econômica, seja no sistema intraregional (no nosso caso entre as novas regiões dentro do Estado de origem) ou no sistema inter-regional (no caso do presente trabalho, entre as novas regiões e as demais unidades da Federação), a literatura mostra que os custos do processo de separação estão diretamente relacionados ao grau de integração. Em outras palavras, quanto maior o nível de integração menor seriam os custos do processo de separação. Não foi objetivo deste trabalho apurar os custos dos possíveis processos de separação. Entretanto, ao fazer a discussão no contexto de matrizes inter-regionais de insumo-produto, foi possível evidenciar o grau de interação tanto em nível intraregional como interregional e, portanto, trazer mais argumentos econômicos para o debate.

Segundo Kuznets (1961), apud in Polése (1981), o crescimento regional de longo prazo, definido como crescimento da renda per capita é, em grande parte, determinado por questões culturais, institucionais e organizacionais. Neste trabalho não objetivamos fazer uma análise prospectiva sobre o comportamento do crescimento regional da nova configuração espacial do país. Entretanto, ao fazer uma análise sobre padrão de transferências governamentais - papel do governo, é possível verificar a contribuição das transferências na composição da renda regional e, portanto, evidenciar ou não a dependência do crescimento da região em relação a este componente da renda.

Assim sendo, dentro do contexto anteriormente mencionado, o objetivo deste trabalho foi trazer novos elementos para a discussão acerca da fragmentação geopolítica do País, que pode vir a acontecer num futuro próximo, e de suas possíveis implicações para a estrutura econômica espacial brasileira. Considerando os papéis das novas unidades da Federação no sistema interregional brasileiro, buscou-se, através de métodos tradicionais de análise regional, identificar padrões hierárquicos e de dependência espacial e produtiva. Os resultados subsidiaram a análise dos impactos da nova configuração das transferências constitucionais, que identificou não apenas os potenciais ganhadores e perdedores dos processos de separatismo em discussão pela sociedade, mas também os mecanismos de interação espacial subjacentes a estes processos.

Este trabalho, de natureza exploratória, teve apenas a pretensão de trazer novos elementos objetivos para o debate. Sob uma perspectiva sistêmica, evidenciou pontos até então desconhecidos sobre os impactos (estáticos/potenciais) produtivos de mudanças na estrutura de transferências constitucionais, trazendo novos subsídios para um tema de implicações ainda mais profundas.

\section{Referências Bibliográficas}

Affonso, R. (1994), 'A crise da federação no brasil', Ensaios FEE 15(2), 321337.

Affonso, R. (2000), 'Descentralização e reforma do estado: a federação brasileira na encruzilhada', Economia e Sociedade 14, 127-152.

Almeida, E. S. (2010), Econometria espacial aplicada, Curso de mestrado em economia aplicada, Universidade Federal de Juiz de Fora. 
Anselin, L. (1995), 'Local indicators of spatial association - lisa', Geographical Analysis 27(2), 93-115.

Dietzenbacher, E., Van Der Linden, J. A. \& Steenge, A. E. (1993), 'The regional extraction method: Ec input-output comparisons', Economic Systems Research 5(2), 185-207.

Haddad, E. A., Luque, C. A., Lima, G. T., Sakurai, S. N. \& Costa, S. M. (2011), 'Impact assessment of interregional government transfers in brazil: an inputoutput approach', Texto para Discussão 09/2011. NEREUS/USP.

Hansen, N. (1978), 'Economic aspects of regional separatism', Papers of the Regional Science Aiissociation 41, 143-152.

Miller, R. E. \& Blair, P. D. (1985), Input-Output Analysis: Foundations and Extensions, 1st edn, Prentice Hall, Englewood Cliffs.

Polése, M. (1981), 'Economic integration, national policies and the rationality of regional separatism.', Canadian Journal of Regional Science 1, 1-19.

Serra, J. \& Afonso, J. R. R. (1999), 'Federalismo fiscal à brasileira: Algumas reflexões', Revista do BNDES 6(9), 3-30.

Souza, C. (1998), 'Intermediação de interesses regionais no brasil: o impacto do federalismo e da descentralização', Dados 41(3).

Souza, C. (2001), 'Federalismo e descentralização na constituição de 1988: Processo decisório, conflitos e alianças', Dados 44(1), 513-560. 